University of Nebraska - Lincoln

DigitalCommons@University of Nebraska - Lincoln

College of Law, Faculty Publications

Law, College of

1993

Justification Defenses And Just Convictions

Robert F. Schopp

University of Nebraska-Lincoln, rschopp1@unl.edu

Follow this and additional works at: https://digitalcommons.unl.edu/lawfacpub

Part of the Legal Studies Commons

Schopp, Robert F., "Justification Defenses And Just Convictions" (1993). College of Law, Faculty Publications. 101.

https://digitalcommons.unl.edu/lawfacpub/101

This Article is brought to you for free and open access by the Law, College of at DigitalCommons@University of Nebraska - Lincoln. It has been accepted for inclusion in College of Law, Faculty Publications by an authorized administrator of DigitalCommons@University of Nebraska - Lincoln. 


\title{
Justification Defenses And Just Convictions
}

Robert F. Schopp*

\author{
TABLE OF CONTENTS
}

INTRODUCTION . . . . . . . . . . . . . . . . . . . . . . 1234

I. THE CONTEMPORARY DeBATE . . . . . . . . . . . . . 1237

A. The Context . . . . . . . . . . . . . . . . . . . 1237

B. Justified Conduct as Right or as Permissible . . . 1239

C. Unknowingly Justified Defendants . . . . . . . . 1241

D. Putative Justification . . . . . . . . . . . . . . 1242

E. The Social Matrix and the Incompatibility Thesis . 1244

F. Duress as a Problematic Classification . . . . . . 1247

G. Summary . . . . . . . . . . . . . . . 1248

II. The Positive Theory Of Justification $\ldots \ldots \ldots \ldots$. 1250

A. Right or Permissible . . . . . . . . . . . . . 1250

B. Knowledge and Justification . . . . . . . . 1257

C. Moral Condemnation and Criminal Punishment . . 1258

1. Five Levels of Condemnation in Criminal Punishment .................. 1258

2. Hard Cases for Moral Condemnation . . . . . . 1262

3. Moral Condemnation and Justification Defenses 1264

D. Knowledge and Justification Revisited . . . . . . . 1267

1. Moral Condemnation, Prohibitory Norms, and

Unknowingly Justified Defendants . . . . . . . 1267

2. Justification Defenses with Subjective Elements 1269

* Assistant Professor of Law and Psychology, The University of Nebraska College of Law

I am grateful to my colleagues Martin Gardner, Josephine Potuto, and John Snowden for comments on previous drafts of this paper and to Dennis Moynihan for capable research assistance. 
Pacific Law Journal / Vol. 24

3. Hard Cases and the Knowledge Requirement . 1278

E. The Social Matrix and the Incompatibility Thesis . 1282

1. Assisting Justified Acts . . . . . . . . . . . 1282

2. The Duty Not to Interfere and the Incompatibility Thesis .................... 1285

3. Hard Cases and the Revised Matrix of Social Responsibility . . . . . . . . . . . . . 1292

III. DuRESS . . . . . . . . . . . . . . . 1300

A. The Classification Problem ............ 1300

B. The Theoretical Interpretation . . . . . . . . . 1302

C. Systemically Complete Mitigation . . . . . . . . . 1308

D. Two Potential Criticisms . . . . . . . . . . . 1313

ConCLUSION . . . . . . . . . . . . . . . . . . 1320

\section{INTRODUCTION}

The fully competent, culpable, and malevolent Spike azttacks Mother Beneficence with a tire iron in order to steal the alms she has collected for the poor. Mother Beneficence defends herself by kicking Spike in the shins, and Dudley Doright rushes to her rescue, punching Spike in the nose, knocking him to the ground, and holding him until the police arrive. Dudley acts solely for the purposes of preventing harm to Mother Beneficence and bringing Spike to justice.

Both Mother Beneficence and Dudley fulfill the offense elements for assault in that they purposely cause bodily injury to another human being. ${ }^{1}$ Most readers, jurors, and theorists would probably agree, however, that they are justified in their actions. The Model Penal Code (MPC) provides justification defenses of self-defense for Mother Beneficence and defense-of-others for

1. See MODEL PENAL CODE § 211.1(a) (Official Draft \& Revised Comments 1985) (defining assault as the purposeful, knowing, or reckless infliction of bodily injury). 


\section{3 / Justification Defenses And Just Convictions}

Dudley. ${ }^{2}$ These defenses would not only exempt Mother Beneficence and Dudley from punishment, they would also ratify their defensive force as correct under the circumstances. ${ }^{3}$

The general characterization of justification defenses as affirmative criminal defenses that ratify the defendant's conduct as acceptable under the circumstances, despite fulfilling all offense elements for some criminal offense, is widely accepted. This formulation distinguishes justification defenses from excuses which exempt the defendant from punishment due to some disability but do not mark the defendant's conduct as acceptable under the circumstances. ${ }^{4}$

Although this broad framework is well-settled, important disputes remain regarding the appropriate classification of hard cases, the parameters of specific justification defenses and of the general category, the moral and conceptual foundations of these defenses, and their significance for the duties and rights of third parties. The defense of duress exemplifies some of these problems in that it is a particularly difficult defense to clearly classify as either a justification or an excuse.

This Article examines the central theoretical issues and difficult cases raised in the contemporary debate regarding justification defenses. The Article also advances a theoretical framework which accommodates these difficult cases and clarifies the parameters of this category of defense. It provides a foundation for this class of defenses in the broader structure of criminal offenses and defenses and in the moral condemnation inherent in criminal punishment. As part of the process of articulating a theory of justification defenses, the Article explores the boundaries that separate justifications from related legal categories, including excuse and mitigation. It does not attempt to develop a comprehensive theory of criminal

2. Id. $\$ \$ 3.04,3.05$ (justifying force necessary to protect oneself or another from unlawful force).

3. G.P. FleTCHER, RETHINKING CRIMINAL LAW 759 (1978) [hereinafter RETHINKING]; P. ROBINSON, CRIMINAL LAW DEFENSES § 24(a) (1984) [hereinafter DEFENSES].

4. RethINkINo, supra note 3, at 759; Defrenses; supra note 3, $\$ \S 24,25$ (identifying justified conduct as at least acceptable); see infra notes 15-23 and accompanying text (discussing the debate among those who consider it only acceptable and those who consider such behavior right or commendable). 
defenses; however, it addresses these related issues only insofar as doing so advances the primary purpose of articulating the contours of justification defenses. ${ }^{5}$

This project pursues both analytic and normative goals. It is analytic insofar as it explicates the broad principles of justification embodied in contemporary American criminal law, but it does not attempt to defend every aspect of current doctrine. It pursues a normative aim in that it advances and defends a theory of justification defenses, including some provisions which would alter current doctrine.

The argument proceeds in the following manner: Section I examines the contemporary debate among criminal law theorists regarding justification defenses. Section I does not defend the position advanced by any of the theorists, but rather, identifies the most contentious issues and cases in the contemporary debate. Section II advances a positive theory of justification defenses and demonstrates that it can accommodate these critical issues and difficult cases in a manner that integrates justifications with the broader purposes and moral foundations of the criminal law. Section III addresses the defense of duress in a manner consistent with this theory, advocating an interpretation of duress as systemically complete mitigation which should generate purely vindicating convictions. The theoretical framework advanced in sections III and III provides a structure for the analysis of justification defenses as part of an integrated system of criminal law. This theory calls upon the condemnation inherent in criminal conviction and punishment, the prospective and retrospective functions of justifications, and the distinction between internal and external justification as broad organizing principles.

5. For a comprehensive discussion of criminal defenses, see DEFENSES, supra note 3. 


\section{The CONTEMPorary DEBate}

\section{A. The Context}

In order to establish the guilt of a defendant for a criminal offense in contemporary American criminal law, the state must prove that the defendant fulfilled the material elements of the offense as defined in the relevant criminal code. ${ }^{6}$ The MPC defines offenses in a manner that includes both objective offense elements stated in the form of conduct, circumstances, or results and culpability elements. ${ }^{7}$ One commits assault, for example, by purposely, knowingly, or recklessly causing bodily injury to another human being. "Causing bodily injury to another human being" constitutes the objective offense elements for assault, ${ }^{9}$ and "purposely, knowingly, or recklessly" represents the culpability element. ${ }^{10}$ In addition, the conduct constituting the offense must include a voluntary act as defined in the MPC. ${ }^{11}$

Defendants may offer several types of defenses in response to the state's case-in-chief. Defendants advance failure-of-proof defenses when they attempt to show that the state has failed to carry its burden of proving one or more offense elements. ${ }^{12}$ Defendants can escape liability despite fulfilling all offense elements by establishing general defenses. For the purposes of this Article, justifications and excuses are the two categories of general defenses of primary interest. Those who raise justification defenses contend that although they have engaged in conduct that fulfills the material elements of a criminal offense, circumstances render that

6. MODEL PENAL CODE $\S 1.12$ (1) (Official Draft \& Revised Comments 1985). The author will refer to the MPC unless reference to a specific code will enhance clarity.

7. Id. $\S 1.13(9)$.

8. Id. $\S 211.1(1)$.

9. Id. $\S 1.13(10)$ (material elements); see DEFENSES, supra note $3, \S 11$ (a) (differentiating objective elements and culpability elements).

10. MODEL PENAL CODE $\$ 2.02$ (culpability elements).

11. Id. $\$ 2.01$. For a more complete discussion of the structure of offense elements, see $R$. SCHOPP, AUTOMATISM, INSANITY, AND THE PSYCHOLOGY OF CRIMINAI RESPONSIBIIITY 86-131 (1991).

12. See DEFENSES, supra note $3, \S \S 21,22$ (discussing a comprehensive system of defenses including those addressed here). 
conduct socially acceptable and perhaps even desirable and, thus, immune from punishment. Excuses, in contrast, address the accountability of the defendant rather than the acceptability of the conduct. Those who raise excuses admit that they engaged in criminal conduct and that this conduct was wrongful in the circumstances, but they contend that they are not appropriately held accountable for that behavior due to some disability-based excusing condition. ${ }^{13}$

In short, justifications appeal to the special circumstances in which the ordinarily criminal conduct was performed, and they exonerate the defendants because the conduct was socially acceptable under these conditions. These defenses would apply to any other actor who performed the same conduct in the same circumstances. Excuses are specific to defendants because they exculpate these individuals for their criminal conduct due to disabilities, such as infancy or psychological disorder, that undermine the attribution of culpability for this particular conduct to these defendants.

Much of the contemporary discussion of justification defenses takes the form of a debate between George Fletcher and a series of critics who raise theoretical criticisms and difficult cases directed at Fletcher's theory. ${ }^{14}$ The critics dispute the following contentions in Fletcher's theory: (1) Justification defenses establish conduct as right rather than as merely tolerable or permissible; (2) only defendants who act with awareness of justificatory circumstances qualify for justification; (3) defendants who commit criminal conduct with the reasonable but mistaken belief that

13. RETHINKING, supra note 3, at 759; DefENSES, supra note $3, \S \S 24,25$.

14. Fletcher presents his theory in several sources: RETHINKINO, supra note 3; The Right and the Reasonable, 98 HARv. L. REv. 949 (1985) [hereinafter The Right and the Reasonable]; The Right to Life, 13 GA. L. REv. 1371 (1979) [hereinafter The Right to Life]; Should Intolerable Prison Conditions Generate a Justification or an Excuse for Escape?, 26 UCLA L. REV. 1355 (1979) [hereinafter Prison Conditions]. The crities include: J. Dressler, New Thoughts about the Concept of Justification in the Criminal Law: A Critique of Fletcher's Thinking and Rethinking, 32 UCLA L. REV. 61 (1984); K. Greenawalt, Distinguishing Justifications from Excuses, 49 LAW \& CONTEMP. PRoBS. 89 (1986) [hereinafter Distinguishing]; K. Greenawalt, On the Perplexing Borders of Justification and Excuse, 84 COLUM. L. REv. 1897 (1984) [hereinafter Perplexing Borders]; P. Robinson, DEFENSES, supra note 3. 
justificatory circumstances exist qualify for excuse rather than justification; (4) justification defenses create a matrix of social responsibility such that other persons may assist and may not resist or interfere with justified conduct; (5) this social matrix generates a corollary incompatibility thesis which holds that no more than one party in violent confrontation can be justified. The following subsections examine each of these contentious issues in order to clarify the parameters of the contemporary debate.

\section{B. Justified Conduct as Right or as Permissible}

According to Fletcher's theory, offense definitions proscribe conduct forbidden by prohibitory norms which constitute morally coherent imperatives for the society to which the law applies. Justification defenses provide a license or permission to violate a general prohibitory norm when certain relatively well defined conditions indicate that doing so will promote a superior right or social interest. ${ }^{15}$ Excuses preclude punishment but excuses are not equivalent to justifications. ${ }^{16}$ Defendants who claim justification rather than excuse contend that their conduct was right or at least permissible, whereas defendants claiming excuse allege that, although their conduct may have been wrong, they should not be held accountable. ${ }^{17}$ Justification defenses enhance the criminal justice system's ability to fulfill some of its important functions.

The criminal law provides both a guide for voluntary self-regulation by individual citizens and criteria for evaluation of that conduct by other citizens and courts. In order to fulfill these functions, justifications should identify the right, rather than merely permissible, option, because doing so enables the individual to determine the correct behavior under the circumstances. ${ }^{18}$ The criminal law seeks to guide individual decision making in such a manner as to avoid violent confrontation and, in order to promote

15. RETHINKING, supra note 3, at 552-77.

16. Prison Conditions, supra note 14, at 1359.

17. RETHINKING, supra note 3, at 854; The Right to Life, supra note 14, at 1376.

18. The Right and the Reasonable, supra note 14, at 976-77. 
this purpose, it avoids rules giving rise to inconsistent claims of rights. Justifications that render the conduct objectively right, establishing the justified actor's right to perform that conduct, prevent conflicts among legally sanctioned acts. If the actor has a right to engage in that conduct, then others have no right to interfere. Thus, justifications that establish objectively right conduct, as opposed to merely permissible behavior, avoid situations in which two parties in conflict might both be justified. ${ }^{19}$.

The critics reject the claim that justifications always identify right conduct which the actor has a right to perform, contending that justified conduct sometimes includes behavior that is merely permissible or tolerable. ${ }^{20}$ The law sometimes allows conduct that is morally less preferable than available alternatives. Most serious criminal offenses involve conduct which harms others. Justifications that alter prohibitory norms by establishing exceptions sometimes identify types of behavior that are not appropriately within the scope of the norms because they do not cause harm of the type proscribed. Some conduct might qualify for exception because it is not harmful, although it is not beneficial, morally ideal, or conduct that the actor has a positive right to perform. ${ }^{21}$

The criminal law does not attempt to promote morally ideal behavior; rather, it establishes a minimal social morality, leaving considerable latitude within which individuals can prefer their own interests over those of others. People can defend themselves with deadly force in their own homes without retreat, for example, and in many jurisdictions, they can also do so in public places. Arguably, this rule provides legal permission for conduct that is only morally tolerable in that retreat to avoid killing would be the morally superior option. ${ }^{22}$ Perhaps the rule allowing the use of deadly force in self-defense against innocent aggressors provides more compelling support for the contention that some justified

\footnotetext{
19. Prison Conditions, supra note 14, at 1358-65.

20. Distinguishing, supra note 14, at 104-05.

21. Dressler, supra note 14 , at 83.

22. Perplexing Borders, supra note 14, at 1904-07.
} 
conduct is merely tolerable rather than superior conduct. At the least, the critics contend, the law ought to be able to provide the justification while leaving open the question regarding whether such conduct is superior or merely tolerable. ${ }^{23}$

\section{Unknowingly Justified Defendants}

Fletcher contends that justifications apply only to those who act with awareness of the justificatory circumstances because justifications exonerate defendants for violations of general prohibitory norms, and only those who act with such knowledge merit exoneration. In some passages, he also seems to demand that they act for the right reasons in that they must be motivated by the justifying conditions. ${ }^{24}$

Paul Robinson contends that current American law reveals no consensus on the knowledge requirement. ${ }^{25}$ According to Robinson, case law is rare and approximately equally divided regarding this issue, and some jurisdictions justify on the basis of defendants' beliefs regarding justifying conditions while others do not. Finally, he interprets the MPC provisions that justify defendants on the basis of their beliefs in the justifying conditions as intended to include putatively justified defendants rather than to exclude unknowingly justified ones.

In addition to disputing Fletcher's position as a descriptive account of current law, the critics support their contention that justifications ought to be available to unknowingly justified actors by appeal to the harm preventing function of the criminal law. ${ }^{26}$ Justification defenses provide exceptions to prohibitory norms for classes of behavior that do not cause the harm the norms are intended to prevent, yet the knowledge requirement would deny the defense to those who do not perform socially harmful conduct as well as to some who actively prevent the relevant harm.

23. Dressler, supra note 14 , at $84-86$.

24. Compare RETHINKING, supra note 3, at 562-65; The Right to Life, supra note 14, at 1382-83 with RETHINKING, supra note 3, at 557, 559; The Right to Life, supra note 14, at 1384-85.

25. DEFENSES, supra note $3, \S 122(\mathrm{e})$.

26. Id. \$122(c); Dressler, supra note 14, at 79. 
Furthermore, the knowledge requirement fails to satisfy Fletcher's purpose of limiting justifications to those who deserve them because it would extend the defense to defendants who are aware of the justifying circumstances but act from vicious motive. Suppose, for example, that $X$ learns of justifying conditions that would provide a defense for force exerted against $Y$. Although $X$ does not care at all about these justifying circumstances, he takes advantage of them in order to exercise his longstanding hatred for $\mathrm{Y}$ by shooting $\mathrm{Y}$. The critics deny that $\mathrm{X}$ 's knowledge merits the license or permission to violate the prohibitory norm and, thus, that it can fulfill the function Fletcher attributes to it. ${ }^{27}$

Kent Greenawalt interprets this problem regarding the unknowingly justified actor as demonstrating that no clear parameters can be drawn for the justification defenses because moral evaluation involves behavior, consequences, and knowledge, blurring the distinction between justification and excuse. ${ }^{28} \mathrm{He}$ offers the hypothetical Ann who attacks Ben out of hate while she is unknowingly justified because Ben was in the process of setting a bomb in a crowded place. Ann provides no grounds for excuse, so her act is either justified or wrongful. Greenawalt contends that Ann's act seems justified if we concentrate on the consequences, but unjustified if we focus on her behavior and reason for acting. He concludes that Ann's action was warranted, although she was wrong to attack Ben. Finally, Robinson argues that extending justifications to unknowingly justified actors who act for evil purposes will not result in gross injustice or social approval of evil actions because these actors remain liable for criminal attempts. ${ }^{29}$

\section{Putative Justification}

Putative justification arises when the actor reasonably but mistakenly believes that the act is justified. Fletcher argues that

27. DEFENSES, supra note $3, \$ 122$ (e); Dressler, supra note 14 , at 80.

28. Distinguishing, supra note 14 , at 95 .

29. See DEFENSES, supra note $3, \S 122$ (d) (discussing attempt liability for those who demonstrate a willingness to cause harm in circumstances that do not result in a net legal harm). 
putatively justified actors should be excused but not justified because including these defendants within the scope of justification would frustrate the violence preventing function of the criminal law by justifying both parties in violent confrontation under certain conditions. ${ }^{30}$ Suppose, for example, that $\mathrm{X}$ reasonably but mistakenly believes that $Y$ is attacking him. If putative justification justifies, then $X$ is justified in responding with force against $Y$, and $Y$, who is unaware of X's mistaken belief, reasonably but mistakenly believes that $X$ is unjustifiably attacking her. Thus, $Y$ is justified by putative justification in responding in kind. As a result, both parties are justified in engaging in armed combat. Should the police intervene in this altercation, they would interfere in mutually justified behavior.

The justificatory approach to putative justification also results in cases in which the actor is not justified in acting in a manner that seems intuitively to be clearly justified. Suppose, for example, that $B$ attacks $C$ because $B$ reasonably but mistakenly believes that $C$ is attacking her. If putative justification justifies, then $B$ is justified, and if C is aware of B's mistake, then C is aware that B's violence against him is justified and, hence, not unlawful. $C$, therefore, may not justifiably exert any force in protecting himself from this unprovoked attack.

For these reasons, Fletcher argues that putative justification should be interpreted as a mistake based excuse that exculpates the defendant for the putatively justified conduct but does not render it lawful. ${ }^{31}$ With this approach, $\mathrm{C}$ can legally defend himself from B's excused but unlawful conduct. B's conduct does not actually serve any superior social interest or right that would ground an exception to the general prohibitory norm and support the matrix of interlocking social relationships created by a true justification.

Greenawalt resists the attempt to consistently categorize putatively justified defendants, arguing that some are most

30. RETHINKING, supra note 3, at 762-69.

31. Id.; Prison Conditions, supra note 14, at 1361-65; see infra notes $35-44$ and accompanying text (explaining the social matrix and the related set of interlocking social rights and duties). 
appropriately justified rather than excused. ${ }^{32} \mathrm{He}$ cites the example of a forest ranger who reasonably but erroneously concludes that he must burn a section of forest in order to create a fire break and protect a town and its inhabitants from a forest fire. Greenawalt contends that the ranger should be justified rather than excused because his choice and action were justified under the circumstances although the consequences fortuitously were not. Any choice that is the best that could be expected under the circumstances should be justified. ${ }^{33}$

Greenawalt advances cases intended to demonstrate the significance of defendants' mental states for justification. ${ }^{34}$ Recall Ann who strikes Ben out of hatred while she is unknowingly justified, and compare her to Anna who strikes Bill because she reasonably but mistakenly believes that he is about to attack her. If justification is purely a matter of the external circumstances without regard to perception, then Ann is justified while Anna is not, yet it seems clear that Ann is blameworthy while Anna is not. Greenawalt contends that Anna's blameless perception should be sufficient for justification and that the fact that Ann would be subject to attempt liability demonstrates that her act was not fully justified. He concludes that actors who act on a faultless appraisal of the facts should be justified.

\section{E. The Social Matrix and the Incompatibility Thesis}

Fletcher's classification of putative justification as excuse rather than as justification reflects his claim that justifications identify conduct that is right despite violating the prohibitory norm. ${ }^{35}$ Any actor would be right to perform such conduct in order to promote the superior right or social interest that justifies it. Excuses, in contrast, are specific to the individual because they arise from the individual's disability rather than from the superior right or interest

32. Perplexing Borders, supra note 14, at 1907-11.

33. Id.; Dressler, supra note 14, at 93.

34. Distinguishing, supra note 14, at 101-03.

35. RETHINKING, supra note 3, at 759-62. 


\section{3 / Justification Defenses And Just Convictions}

that gives rise to the justification. This foundation in superior rights or social interest provides a matrix for a coherent set of complimentary rights and duties for third parties. If person $\mathrm{X}$ is justified in doing act $A$ because doing act $A$ serves the superior right or social interest, then any other person $\mathrm{Y}$ has a right to assist and a duty not to resist or interfere with $X$ in doing $A$ because assisting $\mathrm{X}$ will promote the justificatory right or social interest and resisting or interfering will frustrate that right or interest. ${ }^{36}$ That is, the entire set of related rights and duties cohere with one another because they share a common foundation in the superior social interests and norms that provide the matrix giving form to all rights and duties in the set.

Fletcher's interpretations of justified conduct as right behavior, of putative justification as excuse, and of the social matrix all promote the violence preventing function of law by supporting the incompatibility thesis, which holds that no more than one party to a violent confrontation can be justified. ${ }^{37}$ That is, if a common justificatory right or social interest provides the underlying matrix for a set of related rights and duties, that set should cohere in such a way as to preclude situations in which two or more participants in violent confrontation with each other have access to legal justification. If justification defenses apply only to cases in which justificatory circumstances actually occur, and if third parties have a duty not to resist justified acts, then situations will not arise in which two justified parties engage in violent behavior. If $\mathrm{X}$ and $\mathrm{Y}$ engage in violent conflict, then each resists or interferes with the other. If both were justified, then both would be justified in resisting or interfering with justified actors, in direct contradiction of the claim that one may not resist or interfere with justified actions.

However, the claim that the social matrix provides a coherent set of interlocking duties and responsibilities encounters tension with Fletcher's knowledge requirement. Suppose X is unknowingly

36. Id. at 761-62; The Right to Life, supra note 14, at 77; Prison Conditions, supra note 14, at 1357-65.

37. Prison Conditions, supra note 14 , at 1357-65. 
justified in killing $\mathrm{Y}$ and $\mathrm{Z}$ assists $\mathrm{X}$ in performing that act with knowledge of the justifying circumstances. Due to the knowledge requirement, $X$ has no justification defense, but $Z$ is justified in assisting $\mathrm{X}^{38}$ It seems that it is true both that $\mathrm{Z}$ is justified and that he is not. $\mathrm{Z}$ is justified in that he acts in furtherance of the superior social interest with knowledge of the justifying circumstances, but $\mathrm{Z}$ is not justified in that he promotes $\mathrm{X}$ 's unjustified action.

Critics advance difficult cases calling both the social matrix and the incompatibility thesis into question. Joshua Dressler advances the example in which $X$ is an undercover police officer who believes mistakenly, but with probable cause, that $\mathrm{Y}$ is a mass murderer. ${ }^{39} \mathrm{X}$ draws his gun and approaches $\mathrm{Y}$ in order to arrest her. Before $\mathrm{X}$ has an opportunity to identify himself as a police officer, $\mathrm{Y}$ sees $\mathrm{X}$ draw his gun and reasonably but mistakenly concludes that $\mathrm{X}$ is about to attack her. Dressler contends that it is at least arguable that under these circumstances $\mathrm{Y}$ is justified in defending herself from the apparent deadly attack, and $X$ is justified in defending himself from Y's exercise of force. This example suggests that, contrary to the incompatibility thesis, both parties in a violent conflict might be justified when both act on mistaken perceptions.

Dressler advances other cases that raise doubts about the incompatibility thesis and contends that the resolution of these cases may vary with the underlying moral theory..$^{40}$ Suppose, for example, that $\mathrm{X}$ and $\mathrm{Y}$ are both swimming from their sinking ship toward the only available plank that is floating in the water. It is sufficient to keep either of them afloat, but not both. Dressler contends that it is at least arguable that each party is justified in fighting for her life by preventing the other from gaining the plank. $\mathrm{He}$ advances another example which he interprets as a conflict

38. See Dressler, supra note 14, at $95-96$ (suggesting that we might avoid contradiction here by interpreting X's status as that of one who is justified but lacks standing to assert the defense). If this is true. we need some clarification of the relevant notion of standing and of its place in the larger theory.

39. Perplexing Borders, supra note 14, at 1904.

40. Dressler, supra note 14 , at $88-89$. 
between irreducible values. ${ }^{41}$ Suppose $X$ can save 1000 innocent children only by killing the innocent $Y$. Dressler contends that one could plausibly conclude that $\mathrm{X}$ would be justified in killing $\mathrm{Y}$ and that $\mathrm{Y}$ would be justified in exerting deadly force against $\mathrm{X}$ in self-defense. Thus, both sides in the violent conflict would be acting rightly.

Greenawalt advances actual (as opposed to hypothetical) cases in which he claims both sides in violent conflict might be justified. ${ }^{42}$ In People v. Young, the defendant Young intervened in an apparent mugging that was actually a legal arrest in progress. ${ }^{43}$ Young was arguably justified in that he should be praised rather than blamed for his decision and in that society should encourage people to make similar decisions when confronted with similar information. Yet, the police who violently resisted Young's intervention were also justified in doing so, and society should generally encourage police to resist those who interfere in legal arrests by police officers. Greenawalt presents a similar analysis of prison escape cases in which prisoners might be justified in escaping in order to avoid some imminent violence and prison guards might also be justified in fulfilling their responsibilities by preventing those prisoners from escaping. While Dressler interprets his incompatible justification cases as reflecting tensions among underlying moral theories, principles, and values, Greenawalt explains them as manifestations of the complex process of justifying decisions and acts in light of the information available. $^{44}$

\section{F. Duress as a Problematic Classification}

The defense of duress constitutes a problematic category for any attempt to systematically classify justifications and excuses

41. Id. at $89-91$.

42. Perplexing Borders, supra note 14, at 1919-21.

43. People v. Young, 183 N.E.2d 319 (N.Y. 1962), rev'g 210 N.Y.S.2d 358 (1961).

44. Compare Dressler, supra note 14, at 87-91 with Perplexing Borders, supra note 14, at 1919-21. 
because it contains elements that are ordinarily attributed to each. ${ }^{45}$ Duress is frequently classified as an excuse, but it often includes an objective component such as the MPC's "person of reasonable firmness." ${ }^{26}$ Cases, codes, and commentators vary, addressing duress as an excuse, a justification, or some hybrid combination. ${ }^{47}$ Under the MPC, some cases could fall under both the choice of evils justification and the duress excuse. ${ }^{48}$

\section{G. Summary}

The debate among Dressler, Fletcher, Greenawalt, and Robinson emphasizes the following theoretical issues, with accompanying examples of difficult cases:

(1) Right or Permissible: Do justifications render conduct right or do they include merely permissible or tolerable behavior?

1.1 $\mathrm{X}$ exercises deadly force in self-defense against $\mathrm{Y}$ in $X$ 's house without retreating.

1.2 $\mathrm{X}$ exercises deadly force in self-defense against $\mathrm{Y}$ who is an innocent aggressor.

(2) The Knowledge Requirement: Must defendants be aware of the justifying circumstances in order to be eligible for the defense, or are justifications purely objective in the sense that they are determined by the presence of the justifying circumstances independent of the actor's awareness?

2.1 The unknowingly justified $\mathrm{X}$ attacks $\mathrm{Y}$ out of hate. (Greenawalt's Ann).

(3) Putative Justification: Does putative justification establish a justification, an excuse, or either one depending on other conditions?

45. See infra notes 182-244 and accompanying text (discussing duress and its categorization in a system of defenses).

46. MODEl PENAL CODE $\$ 2.09$ (Official Draft \& Revised Comments 1985); Perplexing Borders, supra note 14, at 1916-17.

47. J. Dressler, Exegesis of the Law of Duress: Justifying the Excuse and Searching for its Proper Limits, 62 S. CAL. L. REV. 1331, 1349-67 (1989) (discussing the various interpretations of the defense of duress).

48. MODEL PENAL CODE $\$$ 2.09, 3.02 (Official Draft \& Revised Comments 1985) (choice of evils and duress, respectively); Perplexing Borders, supra note 14, at 1912-13. 
3.1 $\mathrm{X}$ attacks $\mathrm{Y}$ out of the reasonable but mistaken belief that $Y$ is attacking $X$. (Greenawalt's Anna).

3.2 $\mathrm{X}$ burns a section of forest in the reasonable but mistaken belief that doing so is necessary to save a town and its inhábitants from a forest fire.

3.3 $\mathrm{X}$ and $\mathrm{Y}$ attack one another out of the mutually mistaken but reasonable beliefs that doing so is necessary to defend their lives.

(4) The Social Matrix: Do justifications consistently accompany third party rights and duties such that others may assist justified actors but may not resist or interfere with them?

4.1 Unknowingly justified X kills $Y$ with Z's knowingly justified assistance: $X$ is not justified; $Z$ is both justified and unjustified.

(5) Incompatibility Thesis: Can two or more parties in violent confrontation be justified in exercising force?

5.1 $\mathrm{X}$ attacks $\mathrm{Y}$ out of the mistaken but reasonable belief that $Y$ is attacking a third party and $Y$ responds with force because $X$ is interfering with a lawful arrest. (NY Young case).

5.2 Prisoner $\mathrm{X}$ justifiably escapes in order to avoid imminent violence and Guard $Y$ lawfully uses force to prevent $X$ 's escape. (Prison escape cases).

5.3 $\mathrm{X}$ and $\mathrm{Y}$, swimming from a sinking ship, contest possession of the sole remaining plank.

5.4 $X$ attempts to kill the innocent $Y$ to save 1000 innocents, and $\mathrm{Y}$ attempts to kill $\mathrm{X}$ in self-defense.

(6) Duress: Can duress be consistently categorized as either a justification or an excuse?

Section II advances a theory of justification defenses which addresses these issues and accommodates most of these difficult cases. Section III proposes an interpretation of duress as a separate type of claim which differs from both justification and excuse, and which provides a satisfactory resolution to the remaining cases. These sections refer to the difficult cases identified in this summary 
by number. "Case 2.1," for example, refers to the case of the unknowingly justified Ann who attacks out of hate.

\section{The Positive Theory Of Justification}

\section{A. Right or Permissible}

Fletcher supports his contention that justified conduct is right rather than merely permissible with several arguments. Justified cannot mean merely not liable to punishment because excused conduct is not punishable, yet it is not justified. As an ideal guide for individual conduct, the law should provide a right answer for each situation. If justified conduct is objectively right, the actor has a right to do it and, thus, others have a duty not to interfere. This formulation promotes the purpose of law by avoiding mutually justified violent conflicts. If justified conduct were merely permissible, however, two or more permissible alternatives might conflict, leading to incompatible justifications. ${ }^{49}$ Although these arguments support the interpretation of justified conduct as right rather than merely permissible, difficulties remain for this approach.

Fletcher explicitly contends that justified conduct is right rather than merely permissible or tolerable, but he does not specify a precise interpretation of "right." In one sense, the right act might be understood as the morally best or ideal act. Some teleological moral theories identify the right act as that act which is such that no available alternative is superior. ${ }^{50}$ Justification defenses that identified the right act in this sense would provide the ideal guidance Fletcher seeks in that they would direct the individual toward the best action in the circumstances.

49. See supra notes 15-23 and accompanying text (providing a more complete discussion of the claims summarized here).

50. W. Frankena, EthICs 14 (2d ed. 1973); D. RUNES, Dictionary OF PHILOSOPHY 272 (1962) (explaining teleological theories and the criteria of rightness in those theories). 
As the critics have argued, however, the criminal law generally proscribes harmful acts rather than prescribing ideal conduct. ${ }^{51}$ As a set of specific behavioral directives, the criminal law provides minimal standards rather than ideals of aspiration. If justification defenses identified the morally best conduct, then it would be impossible to surpass the standard set by the justification by foregoing the justified behavior. Yet, under some circumstances, those who refrain from acting on available justifications behave in an heroic, rather than substandard, manner. Suppose, for example, police officer $X$ enters a house to investigate reported gun fire. $X$ encounters a six-year old $\mathrm{Y}$ who has found a loaded gun and killed his sister, apparently unaware that they are not playing a game. When $X$ enters the room, $Y$ laughs, points the gun at $X$, and begins to pull the trigger. $X$ may justifiably shoot $Y$ in self-defense, but if $X$ refrains from shooting, choosing instead to risk lethal injury to himself rather than harming the dangerous but innocent $Y$, most observers would praise $\mathrm{X}$ for heroically rising above the standard set by the law. It seems, therefore, that one can sometimes exceed the standard set by justification defenses, precluding the interpretation of "right" as the morally ideal. ${ }^{52}$

Alternately, one might interpret "right" as morally obligatory. On this interpretation, right conduct is that which one not only may do but also that which one has a duty to do. ${ }^{53}$ This interpretation differs from that which was just discussed because morally obligatory conduct does not necessarily coincide with the best conduct. According to some views, the morally best conduct may be superogatory rather than obligatory. Only a relatively less demanding level of conduct is required. ${ }^{54}$ Individuals are not, however, obliged to take advantage of justifications. The police officer described previously altruistically forgoes an available

51. See supra notes 20-23 and accompanying text (discussing ways in which the criminal law allows acceptable rather than ideal behavior).

52. This case is an example of the type of case listed supra in the summary of $\S$ II as 1.2. A parallel analysis can be presented for those cases listed as 1.1 .

53. See II OXFORD ENGLISH DICTIONARY 2547 (compact ed. 1977) (including the required or necessary way as one definition of 'right').

54. See RUNES, supra note 50, at 306 (explaining the notion of superogatory conduct as that which exceeds the morally required or expected level of performance). 
justification, and other actors may refuse to exercise available justifications for reasons of self-interest rather than of morally or socially superior interest. Suppose X observes $Y$ snatching Z's purse. $X$ is in a position to tackle $Y$ in order to prevent the theft and would be justified in doing so. ${ }^{55} \mathrm{X}$ steps aside rather than risk injury in the confrontation. $X$ refrains from exercising the justification, yet $X$ does not violate an obligation, barring some independent duty to come to Y's aid.

One might interpret right action as including all action that is not wrongful by the appropriate standard. Legally right action, according to this interpretation, includes all action that is not illegal. Although Fletcher apparently would prefer a more stringent formulation of right, this interpretation meets his demand that right mean more than merely not liable to punishment. ${ }^{56}$ Excuses and non-exculpatory policy defenses, such as diplomatic immunity, preclude punishment of the defendants who establish them, but they do not render the offensive conduct permissible. ${ }^{57}$ The law expressly condemns the conduct performed by defendants exculpated under these types of defenses and attempts to prevent repetition through provisions designed to remove these defendants from society or to control their behavior. Insanity defense statutes, for example, provide for post acquittal commitment, and defendants who establish diplomatic immunity are subject to restraint, expulsion, trial and punishment in their own country, or punishment in the host country if the represented country waives immunity.$^{58}$ Thus, actors who establish these types of defenses are not liable to punishment, but the conduct for which they have a defense remains illegal rather than permissible.

55. See MOdel Penal CODE $\$ 3.05$ (1) (Official Draft \& Revised Comments 1985) (justifying force necessary to protect others).

56. Prison Conditions, supra note 14, at 1359.

57. See DEFENSEs, supra note $3, \S 201$ (discussing non-exculpatory defenses as those based on policy considerations other than lack of defendant culpability); id. $\$ 203$ (discussing diplomatic immunity as a defense of this category).

58. MODEL PENAL CODE $\$ 4.08$ (Official Draft \& Revised Comments 1985) (insanity defense disposition); DEFENSES, supra note $3, \S 203$ (c) (discussing the practical effects of diplomatic immunity). 
Fletcher's theory contains the seed from which one can explicate the formulation of justified conduct as permissible. He interprets justifications as modifying prohibitory norms by creating exceptions. ${ }^{59}$ Excuses and non-exculpatory policy defenses merely exempt certain defendants from punishment without modifying the prohibitory norms. Prohibitory norms direct those subject to the norms to refrain from engaging in certain types of conduct. These directives take the following form: 'You may not perform acts of type A,' where the type of act is defined in terms of the conduct or consequences prohibited by the offense definition. Justification defenses create exceptions to these norms by specifying certain circumstances under which the directives do not apply. They take the following form: 'Except when circumstances $C$ occur.' Thus, the modified norm reads: 'You may not perform acts of type A, except under circumstances $C$,' allowing otherwise prohibited acts under specified conditions.

The assault provision of the MPC embodies the following prohibitory norm: 'You may not cause bodily injury to another. ${ }^{, 60}$ The self-defense provision modifies that prohibition by adding the following exception: 'Except under circumstances such that causing bodily injury to another person is immediately necessary for the purpose of protecting yourself against the use of unlawful force by that other person on the present occasion. ${ }^{61}$ By specifying an exception to the prohibitory norm under certain circumstances, a justification defense informs the individual that the norm does not apply under those circumstances. The norm and justification together effectively state: 'You may not perform acts of type A, except that it is not the case that you may not perform acts of type A when circumstances $C$ obtain.' The phrase, 'it is not the case that you may not' is the equivalent of 'you may.' It is not the equivalent of 'you should,' 'you must,' 'it would be best if you did,' or 'it would be morally ideal if you did.' In short, an

59. See supra note 15 and accompanying text (describing Fletcher's position).

60. MODEL PENAL CODE $\$$ 211.1(a) (Official Draft \& Revised Comments 1985).

61. Id. \$ 3.04(1). The author has omitted "believes" from the MPC provision in order to reserve the issue of justificatory knowledge for the section that addresses that issue. See infra notes 95-163 and accompanying text. 
exception to a prohibitory norm allows individuals to engage in conduct of the ordinarily proscribed type, but it does not instruct them to do so or mark conduct of that type as superior or obligatory.

Justifications grant permission or establish privileges by specifying exceptions to prohibitory norms. ${ }^{62}$ The relationship among prohibitory norms, offense definitions, and justifications as exceptions or privileges requires some clarification. If one thinks that offense definitions constitute prohibitory norms and that justifications create exceptions to prohibitory norms, then it seems that justifications create exceptions to offense definitions. Understood in this manner, all offense definitions seem to contain an indefinite number of implicit negative offense elements referring to all possible justificatory circumstances. Justifications then collapse into failure-of-proof defenses because defendants who asserts justification defenses appeal to one of these negative elements, asserting that they did not really commit the offenses with which they have been charged.

The precise interpretation of these concepts intended by the theorists discussed remains unclear. This Article integrates the concepts in the following manner. A prohibitory norm is a broad statement of principle, providing a broadly applicable moral imperative in the conventional social morality represented by the legal system. Offense definitions are more specific legal applications of the prohibitory norm, drafted with consideration for other important social principles and policies to give notice, guide citizens and officials, and articulate the relative severity of various offenses.

A complete set of offense definitions and applicable justification defenses would address the entire universe of behavior relevant to the more abstract moral principles enunciated by prohibitory norms. A fully articulated prohibitory norm would include the central moral principle underlying the offense definition and the various relationships among that principle and the other principles with which it intersects in the comprehensive

62. See supra note 15 and accompanying text. 


\section{3 / Justification Defenses And Just Convictions}

conventional social morality. This network of intersecting moral principles supports the legal structure of offense definitions and justification defenses. ${ }^{63}$

According to this interpretation, justifications do not create implicit exceptions to offense definitions, rendering them failure-ofproof defenses regarding negative elements. Rather, they specify exceptions to the broad prohibitory norm, granting permission to violate offense definitions. Understood in this manner, defendants who fulfill all offense elements for a particular offense under conditions providing a justification defense commit the offense, but they are not liable to conviction, punishment, or condemnation because they have not violated the comprehensive set of norms underlying the offense definition.

As exceptions to the general prohibitory norms, justification defenses take the form of privileges rather than rights. If $\mathrm{X}$ has a right to perform act $\mathrm{A}$, then $\mathrm{Y}$ has a duty not to interfere with $\mathrm{X}$ performing $\mathrm{A}$. However, if $\mathrm{X}$ has only has a privilege to do $\mathrm{A}$, then, although $Y$ has no legal right to stop $X$ from doing $A, Y$ has no legal duty to avoid interference with $X$ doing $A .{ }^{64}$ That is, if $X$ has a privilege to do $A, X$ violates no legal right of $Y$ 's by doing $\mathrm{A}$, but $\mathrm{Y}$ may legally prevent $\mathrm{X}$ from doing $\mathrm{A}$. Privileges allow parties to compete against each other in certain circumstances. For example, in ordinary business or athletic competition, each party pursues some lawful goal while attempting to prevent the other from achieving it. Thus, the privileges created by justification defenses render conduct permissible by establishing exceptions to prohibitory norms, but they do not entail correlative legal duties to refrain from interfering. Fletcher is correct, therefore, in stating that if justification defenses render conduct permissible rather than right, they do not prelude the possibility of conflicting privileges. ${ }^{65}$

63. See infra notes $80-84$ and accompanying text (further discussing the criminal law as embodying a conventional social morality).

64. W.N. HOHFELD, FUNDAMENTAL LEgAL CONCEPTIONS 38-50 (2d ed. 1978).

65. See supra note 19 and accompanying text. 
Although the mere fact that $X$ has a privilege to engage in conduct of type $A$ does not create a duty for $Y$ to refrain from interfering in $X$ 's behavior, it does not follow that $Y$ may legally interfere. $Y$ may have a duty to refrain that arises from other legal sources. Suppose police officer $\mathrm{X}$ causes bodily injury to $\mathrm{Z}$ because $Z$ 's resistance to a lawful arrest renders that injury necessary to the completion of the arrest. X's conduct is justified by the MPC provision privileging the use of force in law enforcement. ${ }^{66}$ Although this privilege does not entail a duty for $Y$ to refrain from interfering, $Y$ retains the duty to refrain established by other provisions. Y's duty to refrain arises from the provisions proscribing assault if $Y$ would interfere in a manner causing bodily injury or from other offence definitions addressing various methods of obstructing official functions. ${ }^{67}$

Those who act on legal privileges, understood as the lack of any duty to refrain from so acting, may encounter situations in which they are privileged to act but others are similarly privileged to resist or interfere with their actions. Perhaps the most obvious cases arise in legally sanctioned boxing matches in which both participants are privileged to exercise force against one another and to interfere with one another's exercise of the privilege. ${ }^{68}$ Similarly, those who engage in legally competitive business practices perform conduct from which they have no duty to refrain but with which others have no duty to refrain from interfering. Yet, the methods of all parties in these instances of mutually privileged competition are limited by all relevant law. Thus, business enterprises may compete with their competitors, but they may not do so through violence. The boxers may exercise mutually privileged violence, but they may not employ weapons. In short, a statute providing a privilege does not preclude the possibility of lawful conflict with other legal behavior, but it does not follow that

66. MODEL PENAL CODE $\S 3.07$ (Official Draft \& Revised Comments 1985).

67. Id. §§ 211.1, 242.1, 242.2, 242.3.

68. Id. \& 2.11(2)(b). 
all privileged conduct may be interfered with or that those who may interfere may do so in any manner they chose. ${ }^{69}$

In summary, justification defenses specify exceptions to prohibitory norms, rendering the justified conduct permissible. Interpretations of justified conduct as morally ideal, superior, or obligatory comport neither with the general logical form of . prohibitory norms and justifications nor with the circumstances in which they sometimes apply. This formulation of justifications as creating privileges leaves open the logical possibility of conflicts between mutually justified actors because the mere fact that conduct is privileged does not preclude legal interference. In order to determine whether this formulation generates instances of mutually justified violent conflict in practice, one must examine the difficult cases in the context of the larger legal structure.

\section{B. Knowledge and Justification}

Fletcher limits justification defenses to those who perform the proscribed action with awareness of the justificatory circumstances, and he interprets putative justification as an excuse. ${ }^{70}$ Thus, the defendant's belief in the existence of the justificatory circumstances is necessary but not sufficient for justification. This formulation is logically consistent, but the critics dispute Fletcher's explanation for the knowledge requirement and advance difficult cases. ${ }^{71}$ Problematic cases include those involving unknowingly justified defendants and putative justification.

Fletcher's argument for the knowledge requirement from the premise that only those who act with such knowledge merit the special exception provided by the defense arguably supports a requirement of justificatory motive as well as knowledge. The knowledge condition would make the defense available to actors who were aware of the justificatory conditions but who acted from

69. See infra notes 137-181 and accompanying text (discussing the social matrix and the incompatibility thesis).

70. See supra notes $24,30-31$ and accompanying text.

71. See supra notes 22-29 and accompanying text (discussing criticisms of the knowledge requirement). 
vicious motives. ${ }^{72}$ Greenawalt raises pivotal cases described earlier as case 2.1 involving the vicious but unknowingly justified Ann and 3.1 involving the putatively justified Anna. ${ }^{73}$ Greenawalt interprets these cases as demonstrating that no clear line separating justifications and excuses can be drawn because moral evaluation addresses behavior, consequences, and knowledge. ${ }^{74}$ Consider also the case of Alice who is both knowingly justified and vicious. Alice accurately perceives that Bert is about to attack Carol. Alice cares not a whit about Carol, but she takes advantage of this opportunity to attack Bert out of hate.

Arguably, common intuitions would hold Anna justified in her action but not Ann or Alice. Fletcher's theory would deprive Ann and Anna of the justification but it would provide Anna with an excuse, while it would justify Alice. Penal codes that base justifications on the defendants' beliefs or reasonable beliefs about justificatory conditions would justify Anna and Alice but not Ann. ${ }^{75}$ Finally, codes that recognized actual necessity or beliefs about necessity as alternative grounds for justification would justify all three defendants, vesting no significance in the important moral differences among them. These cases and the perplexing issues of putative justification and unknowingly justified actors require consideration of the moral condemnation inherent in criminal punishment.

\section{Moral Condemnation and Criminal Punishment}

\section{Five Levels of Condemnation in Criminal Punishment}

Recall the initial clear case of justification involving Spike, Mother Beneficence, and Dudley. ${ }^{76}$. Assume that Spike and Dudley are both charged with assault. Both fulfill all material

72. See supra note 27 and accompanying text.

73. See supra notes 28,34 and accompanying text (describing the cases of Ann and Anna).

74. See supra notes 32-34 and accompanying text.

75. See supra note 25 and accompanying text (discussing contention that there is no consensus on the knowledge requirement).

76. See supra note 1 and accompanying text. 


\section{3 / Justification Defenses And Just Convictions}

elements of the assault offense in that they each purposely cause bodily injury to another. ${ }^{77}$ Neither suffers any disability that would ground an excuse. Each is either justified or guilty. Clearly, Spike is a guilty assailant who deserves punishment, while Dudley merits a justification defense. In what relevant ways do they differ?

Intuitively, Dudley merits praise for his actions while Spike deserves condemnation. Joel Feinberg argues that moral condemnation inheres in the concept of punishment, but the precise nature and focus of the condemnation expressed by criminal punishment remains difficult to specify. ${ }^{78}$ Social institutions of punishment, including the criminal justice system, consist of rules, practices, and roles regarding the nature, justification, and distribution of punishment. Specific applications of the institution of punishment to a particular person at a particular time constitute punishment as events. One can address questions regarding the concept, efficacy, or justification of punishment both at the level of the institution and at the levels of specific application. ${ }^{79}$ Adequate understanding of the condemnation expressed by criminal punishment requires analysis at all levels.

Assume, for example, Spike is tried, convicted, and punished for his assault on Mother Beneficence. At the first level of condemnation, the institutional level, the legal system expresses condemnation of assault by defining it as criminal offense and prescribing criminal punishment. Modern criminal codes might include some offenses which are primarily regulatory and relatively trivial, but the core rules of the criminal law proscribing violations of person and property express widely accepted moral standards within the society. ${ }^{80}$ By setting minimally acceptable standards of morally relevant social behavior that correspond at least roughly with widely accepted moral precepts and by prescribing punishment for violations, a penal code provides an official representation of conventional social morality. Thus, provisions prohibiting certain

77. MODEl PENAL CODE \& 211.1 (Official Draft \& Revised Comments 1985).

78. JOEl FEINBERG, DOING AND DESERVING 95-118 (1970).

79. K. Baier, Is Punishment Retributive?, 16 ANALYSIS 25, 25-32 (1955).

80. MODEL PENAL CODE pt. II (Official Draft \& Revised Comments 1985) (offense definitions primarily address morally relevant conduct); H. MORRIS, ON GUILT AND INNOCENCE 33 (1976). 
types of behavior as criminal offenses express condemnation of those types of conduct as contrary to the conventional morality.

At a second level, legal punishment for violations of the penal code assumes symbolic significance as a social institution for expressing moral condemnation because it marks the recipient as one who has violated the official representation of the conventional social morality. In this manner, the forms of punishment typically applied to those who violate the core rules of the criminal law become the paradigmatic symbols of moral condemnation at the societal level. Execution and imprisonment, for example, take on special significance as symbols of moral condemnation in a society that relies on these modes of punishment for serious crimes against the code.

Criminal punishment as a specific event constitutes an application of this institution to a particular person at a particular time for a specific offense. Society applies the institution to the defendant through the processes of conviction, sentencing, and execution of the sentence. By convicting Spike of this particular assault, the jury reaffirms the more abstract institutional condemnation of this type of conduct. ${ }^{81}$ Condemnation at the third level extends not only to the general type of behavior proscribed by the offense definition, but also to this particular instance of that prohibited type. ${ }^{82}$ Thus, the jury's verdict expresses condemnation of Spike's attack on Mother Beneficence as well as of the general category of assaultive behavior.

A jury might exculpate Spike under the insanity defense if he acted while suffering severe psychological disorder. ${ }^{83}$ Excuses,

81. R.F. Schopp, Wake Up and Die Right: The Rationale, Standard, and Jurisprudential Significance of the Competency to Face Execution Requirement, 51 LA. L. REV. 995, 1031-34 (1991).

82. ALVIN GOLDMAN, A THEORY OF HUMAN ACTION 10-15 (1970). Act-types are general descriptions of certain act-properties that humans can exemplify at a particular time and place. For example, raising one's hand, standing up, and asking a question are all act-types. Act-tokens are specific instances of those types by a particular actor at a particular time. For example, Smith's raising his hand at a particular time is a token of the act-type defined as "raising one's hand." Similarly, Dudley's punching Spike in the nose at a particular time is a token of the act-type defined by the MPC's definitions of assault as "purposely, knowingly, or recklessly causes bodily injury to another." MODEL PENAL CODE § 211.1(1)(a) (Official Draft \& Revised Comments 1985).

83. ScHOPP, supra note 11, chs. 2-6 (discussing the rationale and function of the insanity defense). 


\section{3 / Justification Defenses And Just Convictions}

including the insanity defense, prevent conviction, but they undermine neither the institutional condemnation of the general category of conduct proscribed by the offense definition, the jury's ratification of this systemic condemnation, nor the jury's condemnation of this particular assault. Rather, excuses provide the jury with a method of saying, 'We condemn assaultive behavior in general and this specific instance of it, but you did not commit this offense as a responsible agent.' Thus, the insanity defense exculpates defendants who do not merit condemnation as persons who have violated the law as accountable agents. In contrast, conviction and punishment of a fully culpable defendant convey the fourth level of condemnation of that defendant as one who has violated the law as a fully accountable agent by the standards of this criminal justice system.

The fifth type of condemnation expressed by conviction and punishment in clear cases addresses the defendant as morally blameworthy for wrongful conduct. Absent a finding of severe psychological disorder or some other disability giving rise to an excusing condition, the jury would convict Spike as morally blameworthy. That is, Spike is not only appropriately called to account by systemic standards, he is also morally blameworthy in the eyes of the jury. ${ }^{84}$

In summary, conviction and punishment of a fully culpable defendant for committing a criminal offense and violating a widely accepted moral standard expresses condemnation of five different types at two levels of analysis. First, the offense definition condemns a certain type of conduct at the institutional level by proscribing that type of behavior and prescribing criminal punishment. The second through fourth types of condemnation occur at the level of specific application. The second involves the jury's ratification of the institutional condemnation of the general category of behavior proscribed by the offense definition, and the third conveys the jury's condemnation of this particular instance of the prohibited type. Although both the second and third types of condemnation are expressed by a direct application of the

84. Schopp, supra note 81 , at 1034-35. 
institution, the second type reaffirms the institutional condemnation of the general category, while the third type addresses the specific criminal offense. Fourth, the conviction condemns the defendant as one who committed the offense as an accountable agent by the standards of the system. Fifth, it condemns that defendant as blameworthy for wrongful behavior.

\section{Hard Cases for Moral Condemnation}

In clear cases of unjustified offenses by fully culpable offenders, such as Spike's assault on Mother Beneficence, all five types of condemnation converge in that they clearly apply to this defendant for this offense. Difficult cases arise when circumstances which do not give rise to legal defenses undermine one or more of these five types of condemnation. Juries may struggle, for example, when they encounter a defendant who committed an unjustified and unexcused offense under conditions of great stress or provocation because the jurors may consider the fifth type of condemnation inappropriate. Suppose, for example, that Smith punches Jones in the nose in response to a prolonged series of malicious insults by Jones. Many jurors might think that Jones got what he deserved and that Smith is not blameworthy for the assault, although the provocation would not establish a legal justification or other defense. These jurors would find the fifth type of condemnation undeserved in such a case. Furthermore, jurors who endorse the systemic condemnation of assault as a general category of behavior might deny that this particular instance of that type merits condemnation, considering the third type of condemnation inappropriate as well.

When the official penal code diverges from the widely held conventional morality regarding certain types of behavior, the jury may also consider the second type of condemnation inappropriate in that they might wish to refrain from ratifying the official proscription of conduct of that type. Arguably, certain statutes criminalizing fornication, cohabitation, or possession of marijuana or obscene materials fall into this category in that they express condemnation at the institutional level toward a type of conduct 
that many jurors may not consider appropriate for moral condemnation. If jurors who encounter circumstances such as these accept an obligation to apply the law as they are instructed by the judge, they may convict the defendants although they do not intend to express condemnation of this type of conduct. In certain cases of conscientious civil disobedience, the jurors may consider the behavior acceptable and the defendants unusually praiseworthy. Thus, although all five types of condemnation apply in clear cases with fully culpable offenders such as Spike, punishment may not accurately express condemnation of the second, third, or fifth types under certain circumstances. ${ }^{85}$

In contrast to the second, third, and fifth types of condemnation, the first type, involving condemnation at the institutional level of the general category of conduct, inheres in any institution of criminal punishment because the criminal justice system represents the official conventional social morality for the society in which it is embedded. ${ }^{86}$ Thus, it expresses condemnation of a certain type of conduct by the standards of that official conventional morality when it defines that type of behavior as an offense. Many, if not all, criminal justice systems condition conviction and punishment on retributive requirements of guilt, culpability, responsibility, or desert. ${ }^{87}$ These institutions, including the contemporary American system, establish criteria of accountability as necessary conditions for conviction and punishment. $^{88}$ The fourth type of condemnation, involving condemnation of the defendant as an accountable agent who has violated the legal proscription embodied in the offense definition,

85. See generally id. (further discussing divergence).

86. See supra notes $80-84$ and accompanying text (discussing the criminal law as representing a conventional social morality).

87. See, e.g., MODEL PENAL CODE $\S 2.02$ (Official Draft \& Revised Comments 1985) (requiring culpable mental states for criminal liability).

88. Id. $\S \S 2.01,2.02,4.01$; RETHINKING, supra note $3, \S \S 6.6,10.3$. Note the minimal sense of "retributive" as used here. A system is retributive in this sense if it limits criminal punishment to those who commit offenses while meeting specified conditions of culpability that serve to tender the offense appropriately attributed to the person as a accountable agent. It does not require that the punishment be of similar quality to the harm caused by the offense or that punishment be thought of as restoring a moral balance. See Schopp, supra note 81, at 1020-27 (discussing this sense of retributivism). 
inheres in punishment by these retributive systems because they require accountability by systemic standards as a necessary condition for conviction and punishment. Thus, condemnation of the first and fourth types inheres in criminal punishment by a retributive system.

In summary, the core rules of the criminal law define minimal standards of accepted social conduct by prohibiting certain categories of behavior and prescribing punishment for offenses. A penal code represents an official statement of the conventional social morality. Proscription of a category of behavior and prescription of punishment for it expresses institutional condemnation of that type of conduct from the perspective of that conventional morality. The paradigmatic methods of punishment employed by an institution assume symbolic significance in that they come to represent systemic condemnation. Clear cases of wrongful conduct by fully culpable actors also elicit condemnation of four types at the level of specific application, but only the first (systemic) and fourth (accountability) types of condemnation inhere in all cases of legal punishment by retributive criminal justice systems.

\section{Moral Condemnation and Justification Defenses}

Dudley, in contrast to Spike, deserves praise rather than condemnation because he rescued the innocent Mother Beneficence at his own risk. In order to understand the nature of justification as a defense that renders Dudley inappropriate for conviction and punishment, consider his case in light of the condemnation inherent in criminal punishment and the reasons why that condemnation is not appropriate for him. It seems immediately obvious that Dudley does not merit the fifth type of condemnation in that he is not morally blameworthy for his act. Many would contend that he is praiseworthy for exposing himself to risk in order to rescue Mother Beneficence. This fifth type of condemnation is not inherent in criminal punishment, however, and defendants who are not appropriate for such condemnation sometimes lack a legal defense for their conduct. Some defendants qualify for punishment by 
systemic standards despite being inappropriate for the second, third, and fifth types. ${ }^{89}$

The first and fourth types of condemnation are inherent in criminal punishment, however, rendering conviction and punishment of defendants who do not merit these types of condemnation unjustified. The first type addresses the general category of behavior proscribed in an offense definition rather than a particular act or actor. The fourth type condemns specific defendants who violate the proscription embodied in the offense definition in their capacities as accountable agents by systemic standards. Dudley is a fully accountable agent who qualifies for no recognized excuse and who fulfilled all offense elements in the definition of assault. Dudley purposely caused bodily injury to Spike. It initially appears, therefore, that Dudley qualifies for the fourth type of condemnation. This appearance is deceptive, however, because the first and fourth types of condemnation interact in a manner that significantly affects Dudley's case. The resolution to Dudley's case requires examination of this relationship between the first and fourth types of condemnation.

Any particular act may constitute an instance of many different types of action. Dudley's act of punching Spike, which exemplifies the type of conduct proscribed by the offense definition for assault, also constitutes an instance of the types defined as moving one's arm, swinging one's hand, rescuing Mother Beneficence, and many others. Dudley's act exemplifies both the type proscribed by the offense definition for assault and the type described by the justification defense usually referred to as 'defense-of-others.' This defense applies to those who exercise force necessary to prevent the unjustified use of force by another person against a third party..$^{90}$ Thus, Dudley's conduct exemplifies many types of action, only some of which are subject to the first type of condemnation inherent in offense definitions.

89. See supra notes 76-84 and accompanying text (explaining the relationships between criminal punishment and the five types of condemnation).

90. MODEL PENAL CODE $\$ 3.05$ (Official Draft \& Revised Comments 1985); DEFENSES, supra note $3, \S 133$; see supra note 82 (describing act-types and tokens). 
The objective elements of an offense definition identify the proscribed type of action by describing certain conduct, circumstances, or results. ${ }^{91}$ These elements specify the properties that render an act an instance of the proscribed type. Homicide statutes, for example, forbid acts of the type defined by the property, "causes the death of another human being." Justification defenses create exceptions to the general prohibitory norms underlying the offense definitions in that they identify certain conditions under which conduct exemplifying these properties remains acceptable. The defense provided for the use of force in the defense of others, for example, provides exceptions from the general prohibitory norm underlying the assault and homicide statutes for acts that fulfill the offense elements for these crimes in circumstances that render such conduct necessary to protect another person from the use of unlawful force by a third party. ${ }^{93}$ A fully articulated statement of the prohibitory norm underlying an offense definition would take the form 'do not perform acts of type $T$ unless they are also of type $J$,' where ' $J$ ' specifies the properties an act must possess in order to qualify for an exception provided by a justification. Dudley, for example, struck Spike in a manner that exemplifies the type of behavior proscribed by the offense definition for assault, but his act also constitutes an instance of the exempted category of behavior defined by the justification provided for the defense of others.

The fourth type of condemnation condemns the actor as one who violated a directive of the criminal law as an accountable agent. In order to qualify for this type of condemnation, one must meet two conditions; first, one must violate a directive of the criminal law, and second, one must do so in one's capacity as an accountable agent by systemic criteria. If justifications create exceptions to the prohibitory norms represented by offense definitions, then actors like Dudley, who qualify for justification

91. DEFENSES, supra note $3, \S 11$ (a).

92. MODEL Penal CODE $\S 210.1$ (1) (Official Draft \& Revised Comments 1985).

93. Id. § 3.05; DEFENSES, supra note $3, \S 133$. 
defenses, do not violate the fully articulated prohibitory norms represented by the criminal law.

Both justifications and excuses preclude criminal punishment because they render the fourth type of condemnation inappropriate. This interpretation does not render justification and excuse indistinguishable, however, because each undermines this type of condemnation in a different manner. While justified defendants do not violate a fully articulated prohibitory norm, excused defendants violate such a directive, but they do not do so in their capacity as accountable agents. ${ }^{94}$

In short, excuses exempt certain actors from condemnation and punishment because their conduct that violates the directives of the criminal law is not attributable to them in their capacities as accountable agents by systemic criteria. Justifications preclude condemnation and punishment of actors not because of the merit of the actors but because these defenses exempt certain subsets of generally proscribed categories of conduct from the condemnation expressed at the institutional level by the offense definition. Thus, justified actors do not violate fully articulated prohibitory norms.

\section{Knowledge and Justification Revisited}

\section{Moral Condemnation, Prohibitory Norms, and Unknowingly Justified Defendants}

If justified defendants have not violated the fully articulated norm, then they are immune from punishment for the same reason which precludes punishment of those who simply fail to meet the objective offense elements for any criminal offense. Individuals in either category have not engaged in behavior forbidden by the integrated set of provisions constituting the criminal law. Fletcher correctly argues that unknowingly justified defendants do not merit

94. Schop, supra note $11, \S 6.5$ (discussing attribution of criminal acts to accountable agents). Agents are accountable in this sense if they possess the capacities required for accountability in the criminal justice system. These include, for example, appropriate degrees of consciousness, comprehension, and reasoning. Thus, an action-plan represents an actor as a decision maker, and if the actor meets systemic standards of accountability, it represents him as an accountable agent. 
special exemptions from the general directives. ${ }^{95}$ Justification defenses do not exempt defendants; however, they exempt categories of behavior. Justification defenses alter the general directives represented by the objective offense elements because they exempt certain subsets of the generally proscribed categories of conduct. The fully articulated directive regarding assault and protection of others reads roughly, 'do not cause bodily injury to another human being, unless such conduct is necessary to prevent that other human being from using unlawful force against a third person.' It does not read 'do not cause bodily injury to another human being unless you are altruistically motivated.'

Compare the unknowingly justified defendant to the malicious actor who performs legal activity for vicious reasons. Suppose the Smith family runs a small laundry business that barely makes enough profit to maintain the family. Jones owns a highly profitable chain of commercial laundries which have made him wealthy. Jones opens another store across the street from the Smith laundry purely for the satisfaction of driving them out of business. Jones successfully does so through the legal business advantages derived from greater volume and capital. Jones, like the unknowingly justified defendant, acts from pure malice, but he is immune from conviction and punishment and from the type of condemnation inherent in legal punishment because he has not performed any act prohibited by a fully articulated prohibitory norm.

Some might suggest that Jones differs from unknowingly justified defendants in that he has not violated any general prohibitory norm represented by an offense definition. One who violates a general prohibitory norm, these critics would contend, does not deserve the advantage afforded by the exception unless he acts while aware of it. ${ }^{96}$ To say that a certain class of acts are excepted from a prohibitory norm, however, is just to say that these acts are not prohibited. If justifications create exceptions to general prohibitions, then acts which fall into these categories, like the evil

95. See supra note 24 and accompanying text (discussing Fletcher's argument of meril).

96. This is essentially Fletcher's argument of merit. See id. 
but legal acts of Jones, are not legally prohibited. One cannot consistently say that justification defenses create exceptions to general prohibitory norms and that conduct falling within the scope of the justifications violates those norms. Thus, a person whose conduct falls within the scope of a justification, like a person who performs no conduct violating an offense definition, conforms to the fully articulated prohibitory norm.

Suppose, however, that one were to define justification defenses in a manner that included the knowledge requirement in the description of the exceptions to the general prohibition. Fletcher contends that justifications have objective and subjective elements. Justification defenses exculpate, on this view, because the defendant had good and sufficient reasons for violating the general prohibitory norm. ${ }^{97}$ Fletcher describes the prohibitory norm generated by integrating the general prohibition against homicide with the self-defense justification as, "[t]hou shalt not kill unless thine own life or limb is in great danger." alternative formulation, 'thou shalt not kill unless you know that thine own life or limb is in danger.'

\section{Justification Defenses with Subjective Elements}

If one defines justifications purely in terms of objective circumstances and, further, contends that justifications create exceptions to prohibitory norms and that these justifications are available only to defendants who are aware of those justificatory circumstances, then one faces the difficult task of explaining why the general prohibition applies to some acts that are explicitly excepted from it. By drafting the defense in a manner that includes both objective circumstances and the knowledge requirement in the description of the exempted subclass, however, one avoids this predicament because acts fall into the excepted subclass only if the defendant knows of the justificatory circumstances.

97. RETHINKING, supra note 3, at 576.

98. Id. at 457. 
A thorough evaluation of this proposal requires further elaboration of the role of the fourth type of condemnation in light of the prospective and retrospective functions of criminal offense definitions. These provisions operate prospectively by providing directives to citizens. These directives impose obligations of compliance on citizens and describe the types of conduct individuals must avoid in order to fulfill those obligations. ${ }^{99}$ Although the criminal law enforces these directives through the threat and application of criminal punishment, they probably serve primarily as guidelines for voluntary compliance and only secondarily as retrospective criteria for coercive intervention by the criminal justice system. ${ }^{100}$

When courts apply these directives retrospectively as criteria for criminal conviction and punishment, they must determine whether the defendants performed prohibited acts for which they may fairly be held accountable. Fletcher contends that prohibitory norms and justifications that create exceptions to these norms serve the prospective function, while excuses address only the retrospective function by exculpating those defendants whose conduct cannot fairly be attributed to them as accountable agents. ${ }^{101}$

Fletcher frames prohibitory norms as directives prohibiting conduct such as killing or stealing. ${ }^{102}$ These directives address objective offense elements without culpability elements. ${ }^{103}$ They prohibit certain categories of acts defined by properties specified as conduct, circumstances, or results. Thus, they direct citizens to refrain from performing any specific acts of the type defined by the objective offense elements in the definition of the criminal offense. Individuals who use these norms as guidelines for voluntary compliance must evaluate contemplated behavior in order to determine whether it would constitute an instance of a prohibited type. People act in furtherance of their goals or desires by pursuing

99. Id. at 456-57.

100. Schopp, supra note 81 , at 1011-13.

101. RETHINKING, supra note 3 , at $456-57,491-92$. Presumably the norms and justifications serve both functions because they provide courts with criteria of exculpation when they apply.

102. Id. at 456.

103. See, e.g., supra note 98 and accompanying text. 
action-plans which consist of a set of acts intended to achieve some end. Stated intuitively, they pursue an action-plan in order to achieve some end. ${ }^{104}$

Dudley, for example, punches Spike and restrains him in order to protect Mother Beneficence and facilitate Spike's arrest. Dudley's action-plan consists of the set of acts he selects to achieve his purpose and the decision to engage in that set of acts. The set includes acts that are intended or anticipated as part of the action-plan. Dudley's intended acts include punching Spike, holding Spike on the ground, and yelling "call the police" to a bystander. If Dudley anticipated that yelling to the bystander would startle the bystander but did not yell for the purpose of startling that person, then startling the bystander was an anticipated but not intended component of the action-plan. Acts described as intended and anticipated in the terminology of action-theory correspond roughly to acts performed purposely and knowingly in the MPC. ${ }^{105}$

Had Dudley wanted only to rescue Mother Beneficence and not to facilitate Spike's arrest, he might have chosen to yell at Spike rather than punching him on the expectation that doing so would frighten Spike, causing him to run away. In most circumstances, actors select action-plans to act upon from a wide array of potential action-plans because they believe that the intended and anticipated acts that comprise the plan selected are more likely than those in any available alternative plan to satisfy their complex set of wants and goals. ${ }^{106}$

Offense definitions serve the prospective function of the criminal law by altering the desirability of prospective action-plans. The objective offense elements proscribe certain act-types such as causing the death or bodily injury of another human being. ${ }^{107}$ The

104. Schopp, supra note 11 , at $92-93$.

105. MODEl PENAL CODE $\S \S 4.2,4.3$ (discussing the significance of acts and action-plans for criminal responsibility). The discussion omits the distinction between action-plans and projected act-trees for the sake of brevity. Interested readers can refer to $i d$. $\S \S 4.2,4.3$. Reckless and knowing acts are both anticipated components of the action-plan.

106. Id. The claim is only that people generally seek action-plans that satisfy their wants and goals and not that they systematically review all possibilities for each decision.

107. MODEL PENAL CODE $\$ \S 210.1-210.4$ (Official Draft \& Revised Comments 1985) (homicide); id. § 211.1 (assault). 
moral condemnation inherent in the proscription and the prospect of punishment for performing acts of the proscribed types reduce the probability that actors will select action-plans that include instances of these types as intended or anticipated components. Although actors select action-plans on the basis of the intended and anticipated acts that constitute these plans, the actual results may differ from those intended or anticipated due to error or luck.

In their prospective role as directives regarding future behavior, offense elements address action-plan selection rather than actual conduct. The conduct actually performed by a particular individual is the product of action-plan selection, predictive accuracy, and luck, but information regarding predictive errors and luck is not available to the deliberating agent during the process of action-plan selection. ${ }^{108}$ Thus, the directives represented by objective offense elements are most accurately understood as instructions regarding action-plan selection. As applied to the prospective function, homicide statutes express the directive, 'do not act on action-plans that include intended or anticipated acts that cause the death of another human being. ${ }^{109}$

Action-plans rather than acts most accurately represent actors as decision making agents because action-plans represent the wants, intentions, and expectations of the actors, while actual acts diverge from action-plans due to error or luck. ${ }^{110}$ Culpability elements define a required relation between the conduct forbidden by the objective offense elements and the decision maker as represented by the action-plan. A purposeful culpability element applies to an act directly representing the actor's wants and intentions, while a negligent culpability element represents a less direct relationship between the decision maker's action-plan and the proscribed

108. Information about general accuracy or the probability of errors in these circumstances may be available, but not information regarding the actual errors or luck that will affect the outcome of this decision.

109. Model Penal Code $\S \S 210.2,210.3$ (Official Draft \& Revised Comments 1985) (purposeful, knowing, or reckless homicide); ScHOPP, supra note $11, \S 4.2$ (discussing the relationship between purposeful, knowing, or reckless homicide and intended or anticipated acts on action-plans).

110. SCHOPP, supra note 11 , at 99-100. 
conduct. ${ }^{111}$ Thus, an actor who causes the death of another person by acting on an action-plan that includes killing that person as an intended action commits murder, while one who causes the death of another by acting on an action-plan that would have included killing the other person as an anticipated act if the actor had deliberated with due care commits negligent homicide. ${ }^{112}$

Failure of proof defenses regarding the culpability element exculpate the defendant by demonstrating that the act which exemplifies the proscribed type lacked the relation to the action-plan required by the offense definition and, thus, that this offense carnot be attributed to the actor as an accountable agent. ${ }^{113}$ By undermining the required relation between the actor as an accountable agent and the proscribed conduct, these defenses undermine the fourth type of condemnation discussed previously which condemns the actor as one who violates the criminal law in his capacity as an accountable agent by systemic standards. ${ }^{114}$ Excuses undermine the fourth type of condemnation by undermining the actor's status as an accountable agent, at least as applied to this offense. The insanity defense, for example, exculpates those who fulfill all offense elements while suffering severe psychological dysfunction which renders them incapable of functioning as accountable agents regarding this conduct. ${ }^{115}$ In short, excuses and failure of proof defenses regarding the culpability elements preclude the fourth type of condemnation by defeating the attribution of this offense to this person as an accountable agent. For this reason, both categories of defenses are

111. MODEL PENAL CODE $\S 4.2$ (describing the significance of action-plans for the culpability elements).

112. SChOPP at 95-102; MODEL. PENAL CODE $\S \S 210.1,210.4$ (Official Draft \& Revised Comments 1985) (murder and negligent homicide). One who acts on an action-plan including the homicide as an intended action performs that action purposefully, fulfilling the requirements of the murder statute. One who acts on an action-plan that would have included the homicide as an anticipated act if the actor had exercised due care in selecting the action-plan causes the death through lack of due care; that is, negligently.

113. SCHOPP, supra note 11 , at 106-07; DEFENSES, supra note $3, \$ \S 22,62$ (b) (failure-of-proof defenses).

114. See supra notes $80-84$ and accompanying text (describing five types of condemnation expressed by criminal punishment of clearly culpable offenders).

115. ScHopp, supra note 11 , ch. 6 . 
primarily relevant to courts engaged in the retrospective function of the law.

Justifications, in contrast, address both the prospective and retrospective functions. Justifications serve the retrospective function in that they exempt a subset of acts from the general prohibition expressed by the offense definition, identifying circumstances in which the court should exculpate defendants who fulfill all offense elements. ${ }^{116}$ These defendants do not qualify for the fourth type of condemnation because they have not violated the fully articulated prohibitory norms as formulated by integrating the offense definitions with the justification defenses stated purely as conduct, circumstances, and results. ${ }^{117}$ Unknowingly justified defendants would violate the fully articulated norms if the exceptions created by justification defenses contained both objective elements and a knowledge requirement. These defendants would not qualify for the exceptions provided by justification defenses drafted in this manner because they did not violate the general norm for good and sufficient reasons. ${ }^{118}$

Although unknowingly justified defendants did not violate the general norm for good and sufficient reasons, such reasons were available. That is, circumstances provided good and sufficient reasons for violating the norm, but these defendants did not act for those reasons. In these cases, the available reasons justified the acts that exemplified the proscribed act-types, but the actor's action-plan did not reflect or rely upon these reasons. If, for example, Dudley failed to notice that Spike was attacking Mother Beneficence and attacked Spike only for the purpose of stealing Spike's wallet, then Dudley's conduct would have exemplified the act-type described as rescuing another person from an unlawful use of force, but his action-plan would not reflect that act-type as intended or anticipated. His action-plan would consist of the plan to punch Spike in order to rob him.

116. See supra notes $91-98$ and accompanying text (discussing justification defenses as modifying prohibitory norms).

117. See supra notes $91-94$ and accompanying text (describing fully articulated norms).

118. See supra notes $97-99$ and accompanying text (discussing justification defenses as including objective and subjective elements). 
A justification defense with a knowledge requirement would direct the defense toward the defendant's action-plan by limiting its scope to those who acted on an action-plan that included acts representing the justificatory reasons as anticipated or intended components. The action-plan represents the actor as a decision maker, however, providing the foundation for attributions of accountability, culpability, and blameworthiness. ${ }^{119}$ The action-plan and the manner in which it is selected are critical to excuses and failure-of-proof defenses because these defenses address the attribution of the offense to the actor as an accountable agent by systemic standards of accountability. Thus, a penal code that drafts justification defenses with knowledge requirements conflates the role of justifications with those of excuses and failureof-proof defenses by directing the justification defenses toward the action-plan and the attribution of the offense to the actor as an accountable agent rather than toward modifications of general prohibitory norms.

In adjudicating a claim of justification under a justificatory provision including a knowledge requirement, a court would have to ask two questions: First, was X's act A justified? and second, was $X$ justified in performing $A$ ? The first question addresses the reasons available in the situation for performing $A$ in order to appraise the social acceptability of the act from the external point of view. The second question addresses the reasons that $X$ was aware of in order to appraise $X$ 's decision to engage in the conduct from the internal point of view. ${ }^{120}$ A successful claim of justification under this type of provision would require both external and internal justification.

Although intuitively clear cases of fully justified actors such as Dudley perform actions which are justified from both the internal and external points of view, justification defenses should not require internal justification based on justificatory knowledge for

119. See supra notes 104-112 and accompanying text (discussing the action plan as representing the decision maker's wants and intentions).

120. The author uses the terms "external" and "internal" partially to avoid widespread ambiguity regarding the meaning of "subjective" and "objective" in the discussion of justification defenses. 
at least three reasons regarding the retrospective function. First, as explained above, doing so conflates the role of justifications with those of other defenses by directing the inquiry toward the actor's action-plan and the attribution of conduct to the actor as an accountable agent. Second, although internal justification is relevant to the fifth type of condemnation which addresses the moral blameworthiness of the fully culpable actor for performing the offense, this type of condemnation is not inherent in legal conviction and punishment. ${ }^{121}$ Internal justification would constitute one aspect of a comprehensive moral evaluation, but blameworthiness from this perspective is neither necessary nor sufficient for accountability by the systemic standards of the conventional morality represented by the criminal law. ${ }^{122}$ Third, the knowledge requirement serves primarily to extend liability to some defendants who would otherwise avoid criminal punishment only through luck, but attempt liability applies to these individuals. ${ }^{123}$ Fletcher correctly argues that unknowingly justified defendants do not merit exemption from liability. ${ }^{124}$ Attempt liability provides liability within the conventional morality embodied in the criminal law, however, and moral merit involves the fifth type of condemnation already discussed rather than the first and fourth types which are inherent in criminal punishment.

While these considerations render the knowledge requirement inappropriate for the retrospective function, it is simply unnecessary and redundant for the prospective function. Justification defenses and the general prohibitions they modify serve the prospective function of the criminal law by providing norms for voluntary

121. See supra notes 84-85 and accompanying text and infra notes 214-24 and accompanying text (discussing the significance of condemnation as morally blameworthy for criminal conviction and punishment).

122. See supra notes $80-84$ and accompanying text (discussing the types of condemnation inherent in criminal punishment).

123. DEFENSES, supra note $3, \S 122$ (d). The MPC formulation of attempt liability applies to these cases in that they involve defendants who engaged in conduct that would have constituted an offense if circumstances had been as the defendants believed them to be. MODEL PENAL CODE $₹ 5.01$ (Official Draft \& Revised Comments 1985). The precise scope of attempt liability varies across jurisdictions. For a discussion of various approaches to attempt liability, see W. LAFAVE \& A. SCOTT, JR., CRIMINAL LAW $\$ \S 6.2,6.3$ (2d ed. 1986).

124. See supra note 24 and accompanying text (discussing Fletcher's argument of merit). 
compliance. Individuals who rely on these guidelines in directing their conduct select action-plans intended to avoid behavior that violates the fully articulated norms. The fully articulated norm regarding homicide with the self-defense exception as formulated without the knowledge requirement directs the individual to refrain from acting on action-plans that include acts which cause the death of another human being unless those acts qualify as self-defense. ${ }^{125}$

A knowledge requirement in a justification defense is redundant for the prospective function because all acts in an action-plan are anticipated or intended, rendering it impossible for an actor to act prospectively on an action-plan including an act of self-defense without realizing that it is an act of self-defense. That is, any prospective act of self-defense in an action-plan must be anticipated or intended as an act of self-defense in order to be part of the action-plan as an act of self-defense. Thus, adding a knowledge requirement adds nothing to the norm as applied to the prospective function because the norm directs actors regarding action-plans which include only acts defined by properties the actors are aware of whether or not the knowledge requirement is included. Simply stated, the knowledge requirement is redundant for the prospective function because the process of action-plan selection addresses only anticipated and intended acts. ${ }^{126}$

In summary, excuses, failure-of-proof defenses, and justification defenses undermine the grounds for the moral condemnation inherent in criminal punishment. Justifications preclude this condemnation in a different manner than the other defenses. Excuses and failure-of-proof defenses render this condemnation inappropriate by defeating attribution of the offenses to the defendants as accountable agents, while justifications preclude this

125. See supra notes $91-97$ and accompanying text (discussing justification defenses as altering the fully articulated prohibitory norm).

126. That the action-plan includes only anticipated and intended acts while the knowledge requirement addresses knowledge rather than anticipation does not establish a significant difference between the two. Prospectively, both approaches require awareness that the act is highly likely to be generated; retrospectively, both require that the actor expected that the act which was actually generated would be generated. ScHopP, supra note $11, \S 4.2$. 
condemnation by exempting the actor's conduct from the general proscription. If the justificatory provisions creating those exceptions are drafted purely in terms of conduct, circumstances, and results, then limiting the defense to knowingly justified actors permits condemnation ostensibly for accountable violations of the norms directed toward actors who have not violated the fully articulate norms. ${ }^{127}$ Alternately, justifications drafted with a knowledge requirement avoid this problem, but the requirement is redundant for the prospective function of the norms and it needlessly conflates justifications with other defenses when applied retrospectively. ${ }^{128}$

The approach to the controversy regarding unknowingly justified defendants advanced here relies upon a theoretical framework emphasizing the moral condemnation inherent in legal punishment, the distinction between external and internal justification, and an interpretation of criminal offenses grounded in action-theory. In order to support these organizing principles for the analysis of justification defenses, the next section will apply these principles to the previously identified difficult cases regarding unknowingly justified actors and putative justification. The following sections will apply these principles to the remaining controversial issues and difficult cases, contending that this form of analysis clarifies the parameters of legal justification defenses.

\section{Hard Cases and the Knowledge Requirement}

First, consider the difficult cases involving unknowingly justified or putatively justified defendants such as Ann, Anna, and Alice. These cases elicit troubling intuitions because the actors are neither unambiguously guilty like Spike nor fully justified like Dudley. Recall that Ann, Anna, and Alice attack other persons. ${ }^{129}$

127. See supra notes $91-98$ and accompanying text (discussing justifications and fully articulated norms).

128. See supra notes $98-99$ and accompanying text (discussing justification provisions with explicit subjective elements).

129. See supra notes 28-34 and accompanying text (describing Ann and Anna); supra notes 74-75 and accompanying text (describing Alice). 


\section{3 / Justification Defenses And Just Convictions}

Ann is unknowingly justified, while Anna acts from the mistaken belief that she is justified. Alice realizes that circumstances justify her attack, but she acts out of hate. Arguably, common intuitions would hold Anna but not Ann or Alice justified.

The type of condemnation inherent in punishment and the distinction between internal and external justification are central to understanding these cases. Although it seems intuitively wrong to say that Ann and Alice were justified in acting as they did, their acts were externally justified in the circumstances. Both Ann and Alice were morally blameworthy for acting on malicious motive, but this addresses the fifth type of condemnation involving moral blameworthiness which is not inherent in criminal punishment. Neither is eligible for the critical fourth type of condemnation because neither violated a fully articulated norm. The justificatory circumstances provided external justification for their actions, bringing that behavior within the scope of an exception to the general prohibitory norm created by a justification defense.

Alice, but not Ann, was internally justified in the sense that she was aware of the justificatory circumstances that exempted her conduct from the general norm. Thus, Ann would be vulnerable to attempt liability, but Alice would not because attempt liability attaches to those whose conduct would constitute crimes if the circumstances were as the actors believed them to be. ${ }^{130}$ Ann's attempt liability constitutes the legal system's devise for holding her liable for acting in an internally unjustified manner in circumstances which fortuitously render her action externally justified. Such attempt liability increases convergence between legal liability and common moral intuitions. Alice, like the malevolent launderer Jones, would be morally blameworthy but not subject to condemnation for any offense contained in the conventional morality embodied in the criminal law. ${ }^{131}$ Not surprisingly, common intuitions are more likely to reflect the popular

130. MODEL PENAL CODE $\S 5.01$ (1)(a) (Official Draft \& Revised Comments 1985) (defining attempt liability).

131. See supra notes $74-75$ and accompanying text (describing Alice). 
conventional morality than the official version institutionalized in the criminal law when the popular morality and the law diverge.

Anna, contrary to some people's intuition, lacks legal justification because she violated a fully articulated prohibitory norm. The intuitive notion that Anna was justified by her reasonable but mistaken belief that justificatory conditions applied reflects a judgment of internal justification which addresses both her lack of moral blameworthiness and the attribution of the violation to her in her capacity as an accountable agent by systemic standards. Her lack of moral blameworthiness is relevant to the fifth type of condemnation of an offender as morally blameworthy which is not inherent in criminal punishment. Hence the fact that she does not qualify for that type of condemnation does not in itself preclude conviction and punishment. Her reasonable mistake regarding justification is relevant to the fourth type of condemnation, however, in that it undermines the attribution of her prohibited act to her in her capacity as an accountable agent. That is, the circumstances that led to her reasonable but erroneous belief that she was justified prevented her from selecting her action-plan in light of the relevant information. ${ }^{132}$ Thus, her action-plan did not include an unjustified offense, as defined by the fully articulated norm, as an anticipated or intended component of the plan. Factors that undermine the fourth type of condemnation by virtue of defects in the action-plan, the process of action-plan selection, or the required relation between action-plan and proscribed conduct exculpate the actor, but they do not justify the action. Putative justification provides internal but not external justification, supporting excuse but not a justification defense.

This analysis also accommodates Greenawalt's case involving the forest ranger who burns a section of forest because he

132. In this Article, the author discusses only reasonable mistakes regarding justification. Those who commit unjustified offenses due to reasonably mistaken beliefs are blameworthy for neither the proscribed conduct nor the mistake. Reckless or negligent mistakes regarding justification raise more complex issues with respect to blameworthiness for the mistake and for offenses with recklessness or negligence as culpability elements. See MODEL PENAL CODE § 3.02(2) (Official Draft \& Revised Comments 1985); DEFENSES, supra note $3, \S 184$ (discussing mistakes regarding justification with various degrees of culpability). 
reasonably but erroneously believes that doing so in necessary to save the town. ${ }^{133}$ Greenawalt contends that one ought to be justified in making the best choice in light of all available information. ${ }^{134}$ Indeed, we might suppose the ranger places himself at some danger in carrying out his decision. The ranger is justified in burning the forest, and he is praiseworthy for accepting personal risk in order to carry out his plan. While he is justified in burning the forest, however, burning the forest is not justified. That is, the ranger is internally justified by the reasons he has access to, but the act of burning the forest is not externally justified by all the reasons there are. Some causal factor, such as changing wind conditions, rendered his action unnecessary to save the town and, hence, unjustified. He was internally justified in acting, however, because he was not aware of this factor at the time he was confronted with the decision. In this way, the ranger resembles Anna who was also confronted with a decision in the absence of full information.

The ranger may elicit even stronger intuitive approval than Anna because the story clearly indicates that the ranger is morally praiseworthy for fulfilling what he reasonably understood to be his responsibility at some risk to himself. His moral praiseworthiness renders inappropriate the fifth type of condemnation, however, and this is not the type that inheres in legal punishment. Once one recognizes the distinctions between internal and external justification and between moral blameworthiness and systemic legal accountability, one can describe the ranger as systemically accountable because he possesses the required capacities and as internally justified and praiseworthy for performing acts which are not externally justified. Although the ranger is an accountable agent by systemic standards, his externally unjustified act is not appropriately attributed to him in this status because his reasonable error resulted in his selecting an action-plan on which the intended acts were justified. These conditions preclude the fourth type of condemnation in a manner that grounds excuse rather than

133. See supra notes $32-33$ and accompanying text (discussing case 3.2 , the forest ranger). 134. Id. 
justification. Thus, the ranger is excused from legal liability, and he is morally praiseworthy for his conscientious decision and effort.

The final difficult case regarding the knowledge requirement involves $\mathrm{X}$ and $\mathrm{Y}$ who attack one another out of mutual mistakes, generating a conflict between two putatively justified actors. ${ }^{135}$ Each actor is internally but not externally justified. Interpreted in this manner, these cases create no problem of conflicting justifications because each lacks the external justification that supports a justification defense, although each may be eligible for excuse. $^{136}$

E. The Social Matrix and the Incompatibility Thesis

\section{Assisting Justified Acts}

Fletcher contends that justifications modify prohibitory norms, creating a complex matrix giving rise to a complex set of related social responsibilities. Third parties may assist justified acts, and they may not resist or interfere with these acts. ${ }^{137}$ This claim seems intuitively plausible in that justified acts are legally permissible acts, and there is no obvious reason why one may not assist another in performing a legal act or why one may interfere with a legal act. Dudley illustrates the positive aspect of this matrix in that he justifiably assists Mother Beneficence in her justified exercise of self-defense. Any third party who interfered with Mother Beneficence and Dudley by entering the fray in support of Spike would have violated the negative aspect which proscribes interference with justified conduct such as that of Mother Beneficence and Dudley.

135. See supra notes 30-31 and accompanying text (discussing case 3.3, mutually justified violent confrontation).

136. See supra notes 12-13 and accompanying text (differentiating justification and excuse).

137. See supra notes $35-36$ and accompanying text (describing the social matrix and related rights and responsibilities). 
The incompatibility thesis holds that two parties in violent conflict with one another cannot both be justified. ${ }^{138}$ The incompatibility thesis can be understood as a corollary of the negative aspect of the social matrix. Two parties in violent conflict each interfere with the other; if either is justified, then the other interferes with justified conduct and cannot be justified according to the social matrix. Therefore, no more than one party in the conflict can be justified.

This thesis apparently works well when applied to Spike's attack and the resulting conflict. Mother Beneficence is justified but Spike is not. Dudley assists Mother Beneficence by interfering with Spike, creating a second conflict in which Dudley is justified but Spike is not. Should some third party misunderstand the situation and intervene to protect Spike from Dudley, that person could not be justified because she would interfere with Dudley who is justified. She may, however, qualify for an excuse if she reasonably misinterpreted the situation. ${ }^{139}$

When combined with the requirement that the justified defendant act with justificatory knowledge, the social matrix encounters difficulty with cases in which $\mathrm{Z}$ knowingly assists the unknowingly justified $\mathrm{X}$ in killing $\mathrm{Y}$. If $\mathrm{X}$ lacks justification because he lacks justificatory knowledge, then it seems that $Z$ is both justified and unjustified. $\mathrm{Z}$ is justified in that she acts with knowledge of the justificatory circumstances, and she is unjustified in that she assists in X's unjustified killing of $\mathrm{Y}^{140}$ The distinction between internal and external justification allows one to resolve this type of problem regarding the social matrix. X's killing of $\mathrm{Y}$ is externally justified by all of the relevant reasons that actually apply, although $\mathrm{X}$ is not internally justified by the reasons

138. See supra notes 35-37 and accompanying text. Some conflicts can involve additional parties who participate as principals in more complex conflicts or as assistants to the primary parties; however, I will use this simple formulation. In addition, the thesis must be understood as limited to illegal conflicts, with legal contests such as boxing matches of football games falling beyond the scope of the claim.

139. See supra notes $129-136$ and accompanying text (discussing putative justification as an excuse).

140. See supra note 38 and accompanying text (describing case 4.1 , where $\mathrm{Z}$ is apparently both justified and unjustified). 
of which he is aware. Although the act that $\mathrm{X}$ actually performs is a member of an exempted subset of behavior generally proscribed by the prohibitory norm, he acts on an action-plan which includes an act of the proscribed type as an intended act. X's action-plan renders him morally blameworthy because the plan represents $X$ as an accountable agent. ${ }^{141}$ The criminal law distributes punishment for committing proscribed conduct as an accountable agent, however, not for being a person who acts on reprehensible motives. In this matter, $\mathrm{X}$ resembles the malevolent launderer Jones who engaged in reprehensible but legal conduct for malicious motives. ${ }^{142} \mathrm{X}$ remains vulnerable to attempt liability which applies to those who act on action-plans intended to produce proscribed conduct. Attempt liability expresses the systemic condemnation of such action-plans and of those who act on them. ${ }^{143}$

$\mathrm{Z}$ is both internally and externally justified. Her action-plan exemplified the exempted subtype that $X$ actually performed (justifiably killing) rather than the proscribed type of conduct (unjustified killing) that $X$ intended. The apparent contradiction regarding Z's action is illusory because she is internally justified by the reasons she is aware of and she is externally justified by all relevant reasons. She assisted $X$ in the externally justified act he actually performed rather than in the internally unjustified act he intended.

This resolution of Z's case demonstrates why third parties may justifiably assist justified acts. This third party permission arises from the external justification of the act, and not from the original actor's internal justification in performing the act. The third party who assists another in performing a justified act stands in a position analogous to an accomplice to a legally permissible

141. See supra notes $104-112$ and accompanying text (discussing action-plans as representing actors as agents).

142. See supra notes $95-96$ and accompanying text (describing Jones).

143. See supra notes 29,123 and accompanying text (discussing attempt liability and putative justification). 
act. ${ }^{144}$ That is, the third party behaves as an accomplice to an act which exemplifies an exempted sub-type of the generally proscribed behavior and which, therefore, does not violate the prohibitory norm. These third parties do not qualify for the fourth type of condemnation because they have neither committed nor assisted legally proscribed conduct. Their intentions and motives determine whether they qualify for attempt liability or moral blame. $^{145}$

\section{The Duty Not to Interfere and the Incompatibility Thesis}

In addition to the right to assist justified acts, the complete social matrix includes the duty not to resist or interfere with justified acts and the associated incompatibility thesis. ${ }^{146}$ Critics attack the duty not to resist or interfere and the incompatibility thesis by advancing difficult cases which constitute putative counter-examples to the duty and to the thesis in that two or more parties are arguably justified in interfering with one another in a violent confrontation. ${ }^{147}$ If one accepts both parties' action as justified, these cases defeat the duty not to resist justified action because each party is justified in acting in a manner that interferes with the other's justified action, and they defeat the incompatibility thesis because both parties to a violent confrontation are justified.

In one case, the defendant Young came to the aid of an apparent mugging victim who was actually struggling with two police officers attempting to complete a lawful arrest. One of the police officers was injured in the ensuing struggle, and Young was convicted of criminal assault. ${ }^{148}$ Greenawalt advances this case as one involving a violent conflict among justified actors. The police were justified in making a lawful arrest and in resisting Young's

144. MODEL PENAL CODE $\S 2.06(2)$-(3) (Official Draft \& Revised Comments 1985) (providing for accomplice liability).

145. See supra notes 29,123 and accompanying text (discussing attempt liability).

146. See supra notes $35-37$ and accompanying text (describing this duty and the incompatibility thesis in Fletcher's theory).

147. See supra notes $39-44$ and accompanying text (describing these putative cases of justified interference or mutually justified violent conflict).

148. People v. Young, 183 N.E.2d 319 (N.Y. 1961), rev'g 210 N.Y.S.2d 358 (1962). 
interference with that arrest. Yet, Young was justified in intervening in what he reasonably believed to be a mugging because, surely, society wants to encourage rather than condemn the willingness of citizens to protect one another from mugging. ${ }^{149}$

Young was not justified in interfering with a lawful arrest, and this is the type of action that his conduct actually exemplified. Yet, Young acted on an action-plan which included as an intended act an act of rescuing a mugging victim but not an act of interfering with an arrest. Young's conduct exemplified the act-type proscribed by the offense definition for criminal assault, but the intended act on his action-plan exemplified the exempted sub-type represented by the justification for defense of others. The intuitive judgment that Young does not deserve condemnation for acting as he did reflects his action-plan which represents him as an accountable agent, providing the appropriate focus for attributions of desert. Thus, Young was internally justified in acting on his action-plan, although his act that actually resulted was not externally justified.

Young was not culpable for his unjustified act, either by the standards of ordinary critical morality or by the standards of the conventional morality represented by the criminal law. ${ }^{150} \mathrm{He}$ is not a proper subject of the fourth type of condemnation inherent in criminal punishment because his reasonable mistake regarding justification prevents attribution of his externally unjustified offense to him as an accountable agent. This reason for withholding condemnation supports the excuse of putative justification based on mistake rather than justification, however, thus rendering the apparent conflict between mutually justified actors illusory. The police officers were both internally and externally justified in pursuing the lawful arrest and in resisting Young's interference in that arrest. The police officers and Young were internally justified, but only the officers were externally justified. Thus, the case

149. Perplexing Borders, supra note 14, at 1919-20. This case also provides an example of the same type as the difficult case listed as 3.3 in the summary list of $\S$ II.

150. JOEL FEINBERG, HARMLESS WRONGDOING 124-26 (1988) (distinguishing critical morality as correct or rationally defensible morality and conventional morality as the set of rules and principles actually established and accepted in a society). 
represents a conflict between the justified use of force and excusable force. This case demonstrates that it distorts the social matrix attributed to justification defenses to say that only one party to a violent conflict can be justified. More than one party to the conflict can be internally justified, but this social matrix precludes the possibility of conflicting externally justified acts.

Certain prison escape cases also present difficult challenges to the social matrix and to the incompatibility thesis. Courts and commentators disagree regarding the application of justification defenses to prison inmates who escape from incarceration in order to avoid impending violence. ${ }^{151}$ If one contends that these defendants are justified under the general justification available to those who choose the lesser evil, these cases seem to violate the incompatibility thesis in that prison officers who attempt to prevent these escapes act in pursuit of their legal responsibilities and within the scope of the justificatory defense available to those who use force in law enforcement. ${ }^{152}$ This interpretation arguably justifies both sides of a violent conflict.

This apparent conflict between two justified parties only arises in certain limited conditions. If the prisoner can avoid the violence that constitutes the greater evil by fleeing from a cell or common area to the custody of the officials, the conflict does not arise. Under those circumstances, only flight to the officials is justified by the defense, and the officials' fulfill their duty by accepting custody of the prisoner. The difficult conflicts arise when the prisoner can avoid the violence only by escaping from the custody of officials.

One might argue that the officials should be excused rather than justified in their use of force. According to this line of argument, the prisoner's justified escape constitutes legal activity under an exception to the norm proscribing escape. The officials who

151. See, e.g., D. Dolinko, Comment, Intolerable Conditions as a Defense to Prison Escapes, 26 UCLA L. Rev. 1126 (1979); Prison Conditions, supra note 14 (exemplifying this debate).

152. MODEL PENAL CODE $\$ 3.02$ (Official Draft \& Revised Comments 1985) (choice of evils); id. § 3.07(1), (3) (justified force in law enforcement). The MPC includes "believes" language, but in light of the previous discussion of putative justification, the author treats these provisions as requiring actual necessity. 
exercise force in resisting this escape do so under the reasonable but mistaken belief that the escape is unlawful, and thus, they fall under the excuse provided for putative justification. This interpretation may strike many readers as inadequate for two reasons. First, it apparently licenses escalating violence by the justified escapees as they exert the force necessary to accomplish their justified ends and to protect themselves from the excused but unjustified force directed at them by the officials. Second, it seems inadequate to say that the officials engage in wrongful but excusable conduct when they act in pursuit of the responsibility with which the legal system charges them.

Alternately, one might argue that the escapees should be excused rather than justified. ${ }^{153}$ This interpretation also encounters difficulties, however, because the justificatory choice of evils defense appears to most clearly apply to at least some of these cases in that the escapees commit relatively less serious escape offenses in order to prevent more serious murders or sexual assaults. ${ }^{154}$ Such escapes to avoid murder or sexual assault seem to merit exculpation, even if the escapees act without the disability or extreme fear that would ordinarily ground excuse. In short, it is difficult to explain why defendants should be excused rather than justified in circumstances in which they lack the disability that usually grounds excuse and in which the specific defense that most accurately applies is the justificatory defense for choice of the lesser evil rather than an excuse. ${ }^{155}$

Finally, one might deny the incompatibility thesis, contending that both parties are justified, but this position legitimizes mutual violence, apparently violating the matrix which purports to establish a set of compatible rights and duties. ${ }^{156}$ Although this interpretation frustrates the criminal law's function of preventing

153. Prison Conditions, supra note 14.

154. Compare MODEL Penal CODE § 242.6(4) (Official Draft \& Revised Comments 1985) (escape as a third degree felony) with id. $\S 210.2(2)$ (murder as a first degree felony) and id. $\S$ 213.2(1) (forced deviate sexual intercourse as a second degree felony).

155. Some commentators would argue that duress is the most appropriate defense and that coercion provides the disability. See infra notes 182-244 and accompanying text (discussing duress).

156. See supra notes 35-37 and accompanying text (describing the social matrix). 
violent confrontation, however, the criminal law pursues a complex set of purposes, and there is no reason to assume that any possible interpretation can completely satisfy all of them. The criminal law is intended to prevent crime and to limit punishment to culpable offenders, for example, and certain defenses and procedural devises designed to promote the latter goal may frustrate the former. ${ }^{157}$ Furthermore, the potential for mutually justified violence in prison escape cases interpreted in this manner does not arise from a defect internal to the theoretical formulation of justification defenses. Rather, it reflects a tension between these defenses and the provisions that license arrest and detention.

The social matrix and the incompatibility thesis appropriately apply to justification defenses defined in terms of actual necessity, with reasonable but mistaken belief regarding necessity giving rise to excuse for putative justification. ${ }^{158}$ Statutes authorizing the use of force by officers in arrest, detention, or escape prevention ordinarily apply to any lawful arrest or detention. ${ }^{159}$ Lawful arrest by a law enforcement officer ordinarily requires reasonable grounds to believe that the subject has committed a crime. ${ }^{160}$ Thus, authorization to use force in law enforcement requires only belief regarding the relevant conditions even if justification defenses require actual necessity. These provisions collapse external justification into internal justification by authorizing arrest on the basis of reasonable belief. That is, they create an exception to the general prohibitory norm against the use of force, but they do so on the basis of the officer's reasonable beliefs regarding the grounds for arrest. By virtue of these provisions, arresting officers qualify for exceptions to the general prohibitory norms on the basis of internal rather than external justification. Potential cases of mutual justified violence during prison escapes reflect this contrast

157. One might plausibly argue, for example, that the insanity defense limits punishment to culpable offenders at the expense of creating a loophole through which some guilty defendants escape punishment and continue to commit crimes. Similarly, one might contend that restrictions on searches, seizures, and confessions limit the state's ability to secure convictions and prevent crime.

158. See supra notes $95-136$ and accompanying text (discussing justification and putative justification).

159. MODEL PENAL CODE $\$ 3.07(1)$, (3) (Official Draft \& Revised Comments 1985).

160. LAFAVE \& SCOTr, supra note $123, \S 5.10$ (a). 
between justification defenses grounded in necessity and arrest authorized by the arresting officers' reasonable beliefs.

These conflicts between externally justified justification defenses and internally justified exercises of force in law enforcement are not unique to prison escape cases. Suppose, for example, that $X$ sees terrorist $Y$ bringing a bomb into a crowded building in a baby carriage. $X$ knocks $Y$ down, and rushes from the building with the carriage in order to prevent harm to the other occupants when the bomb detonates. Police officer $Z$ witnesses $X$ 's conduct and attempts to stop and arrest $X$ in the building. $X$ is justified in her assault on $Y$ and in taking $Y$ 's property from the building by the justificatory defenses addressing defense of others and choice of evils, but $\mathrm{Z}$ is also authorized in exercising force against $X$ in making an arrest based on reasonable belief. This conflict between legal acts reflects the potential tension between externally justified justification defenses and internally justified arrest.

These cases suggest that justification defenses create a matrix of social responsibility, but the claim that others may assist justified acts and may not interfere with such acts misstates the parameters of the matrix. Consider the clear case of force justifiably exercised by Dudley against Spike. Suppose that as Dudley approaches Spike and raises his fist to strike, Spike immediately ducks, falls to the ground, and surrenders. Alternately, suppose officer Fife steps between Dudley and Spike, restraining and arresting Spike. In each case, Spike or officer Fife interferes with Dudley's justified use of force by evading it or by rendering it unnecessary and therefore unjustified. ${ }^{161}$

Neither Spike nor officer Fife would have been justified if they had intervened by hitting Dudley. Dudley's justification defense does not preclude others from justifiably interfering with Dudley's conduct; rather, it precludes their interfering through force directed against Dudley. Dudley's defense renders lawful his otherwise

161. See II OXFORD ENGLISH DICTIONARY 1462 (compact ed. 1977) (to interfere is "to come into collision or opposition, so as to affect the course of; . . . to interpose, take part, so as to affect some action"). Interference implies opposition, but not necessarily violence. 
illegal use of force, and therefore, Dudley's use of force does not carry the justificatory significance of unlawful force. That is, it does not justify responsive conduct, such as defensive force, that would otherwise have been illegal. Others remain free, however, to interfere with Dudley's justified conduct through actions authorized by statute (Fife's arrest of Spike) or through behavior that is not forbidden (Spike's ducking).

In short, justification defenses do not preclude others from resisting or interfering; rather, they eliminate any justificatory significance that the actor's conduct would otherwise have had regarding ordinarily illegal means of resisting or interfering. Because Dudley's use of force against Spike was justified, it does not justify the use of otherwise unlawful force by Spike or Fife against Dudley. Dudley's justification defense does not, however, preclude interference by means that do not rely on Dudley's force for their justification. Thus, justified actors can sometimes come into mutually justified violent conflict with law enforcement officers precisely because the officers' use of force draws its justification from statutory authorization and the officers' beliefs rather than merely from the actors' behavior.

Just as the justification defenses do not categorically preclude resistance, they do not categorically legitimize assistance. Although Dudley is justified in assisting Mother Beneficence in defending herself, he may not do so through any means he pleases. Spike's attack would not have justified Dudley in ramming the bus he was driving into Spike and ten innocent bystanders. Similarity, if $X$ were shooting at $Y$ from a rooftop, $Z$ would be justified in loaning $\mathrm{Y}$ a rifle with which to shoot back but not in blowing up the building and its occupants. Y's justification does not authorize $\mathrm{Z}$ in assisting $Y$ through any means possible; rather, it renders $Y$ 's use of defensive force legal and therefore precludes accomplice liability for Z's assistance in that conduct. Y's justification defense prevents Z's otherwise legal conduct from becoming illegal merely by virtue of the fact that it constitutes assistance to Y's use of force. In contrast, any act performed by $\mathrm{Z}$ for the purpose of 
promoting an illegal use of force by $\mathrm{Y}$ would elicit accomplice liability. ${ }^{162}$

In summary, justification defenses create exceptions to prohibitory norms, establishing a revised matrix of social responsibility giving rise to the following set of rights and duties. First, $\mathrm{Z}$ may assist $\mathrm{Y}$ in a justified exercise of force against $\mathrm{X}$ without becoming liable merely by virtue of having assisted. Second, if $Z$ resists or interferes with Y's justified exercise of force through otherwise illegal means, $Z$ may not justify that conduct by appealing to Y's use of force. Stated differently, conduct justified by a justification defense neither grounds accomplice liability for those who assist through otherwise legal behavior, nor does it provide justification for those who resist or interfere with the conduct through otherwise illegal conduct.

\section{Hard Cases and the Revised Matrix of Social Responsibility}

Dressler challenges the incompatibility thesis with two additional types of hypothetical cases. The first involves only innocent parties. A dam collapses, sending a torrent of water rushing down a valley toward a town populated by 1000 innocent people. B can save the innocent inhabitants of the town only by immediately detonating an explosion that will redirect the water away from the town but toward the innocent $\mathrm{C}$ who is farming by himself in the next valley. $\mathrm{B}$ must decide whether to detonate the explosives causing the death of the innocent $\mathrm{C}$ or to refrain from doing so, resulting in the deaths of the 1000 innocent townspeople. $\mathrm{C}$ accurately perceives the entire situation and sees $\mathrm{B}$ reach for the detonator. $C$ realizes that he can save his own life only by shooting $\mathrm{B}$ before $\mathrm{B}$ detonates the explosion. Arguably, this case violates the incompatibility thesis because the lesser evils defense justifies $B$ in

162. MODEL PENAL CODE $\S 2.06$ (Official Draft \& Revised Comments 1985) (addressing accomplice liability). 
detonating the explosion, and self-defense justifies $C$ in shooting $B$ in order to prevent $B$ from killing $C_{\text {. }}{ }^{163}$

A mechanical application of the revised social matrix as interpreted above encounters no difficulty with this case. The lesser evils defense justifies B's action, rendering it legal. Self-defense justifies force only in response to unlawful exercises of force, and $B$ 's justified act does not fall into this category. ${ }^{164}$ The revised social matrix prohibits C's shooting of B in that C's ordinarily unlawful act of shooting another person can draw no justification from B's justified act. No conflict of justified acts occurs here because $B$ is justified while $C$ is not. In order to appreciate the force of this example, however, one must understand it as a proposed intuitive counter-example to the social matrix as a component of conventional social morality. Should a society require that an innocent party refrain from resisting the sacrifice of his life to save others? Can one plausibly say that an innocent party acts wrongfully rather than justifiably in attempting to prevent others from sacrificing his life?

Consider a modified version of this case. This revised story is identical to the original with one exception. A third party $\mathrm{D}$ rather than $C$ perceives the situation and must decide whether to allow $B$ to redirect the water, killing the oblivious $\mathrm{C}$ or to shoot $\mathrm{B}$, saving $C$ but accepting the deaths of $B$ and 1000 townspeople. What would justify $D$ in rescuing $C$ at the expense of 1001 innocent lives? All parties are innocent victims of a natural disaster. The decision apparently involves an unavoidable choice between one innocent life and 1001, with no additional morally relevant factors to consider. If $\mathrm{D}$ would not be justified in rescuing $\mathrm{C}$ at the expense of 1001 lives in the revised case, what legally recognized

163. This case represents an elaboration of the type of case listed as 5.4 and introduced into the contemporary justification debate by Dressler, supra note 14, at $89-90$. Although some jurisdictions except homicide from the lesser evils defense, neither the MPC nor Robinson adopt this exception. See MODEL PENAL CODE $\$ 3.02$ (Official Draft \& Revised Comments 1985); DeFENSEs, supra note 3, \& 124.

164. MODEL PENAL CODE $\$ 3.02$ (Official Draft \& Revised Comments 1985) (choice of evils); id. $\$ 3.04$ (self-defense). 
justificatory significance lies in the mere fact that the roles of D and $\mathrm{C}$ reside in the same person in the original story?

Although the framework advanced here accommodates this case without generating an instance of legally justified violent conflict, the intuitive discomfort elicited by the case remains. The proposed resolution is theoretically consistent, but it is simply not fair to C. Clear cases of fully justified violence, such as Dudley's conduct toward Spike, demonstrate both internal and external justification, and this justification is symmetrical. A symmetrically justified act treats all parties justly, all things considered. That is, no individual suffers undeserved injury. ${ }^{165}$ Dudley's conduct elicits intuitive consensus both because Mother Beneficence is an innocent victim who merits rescue and because Spike deserves what he gets. Some cases such as this one involving $B$ and $C$ or those addressing selfdefense against innocent aggressors elicit ambivalent intuitive responses just because some party suffers undeserved injury regardless of the choice made.

Perhaps an ideal moral world would be free of undeserved injury, but justification defenses, and the criminal law generally, pursue a more modest aim. According to the theory advanced in this Article, justification defenses exculpate defendants who do not merit the fourth type of condemnation because they do not violate a fully articulated prohibitory norm. ${ }^{166}$ Many acts result in undeserved injury to some party without violating any legal norm. The malicious launderer Jones, for example, inflicted undeserved harm on the Smith family without violating any legal norm. ${ }^{167}$ Benevolent as well as malevolent actors sometimes inflict undeserved injury without violating any legal norm. Suppose $X$ drives legally and carefully along a residential street but hits a child who darts into the street from between two cars in a manner that would prevent the most skilled and careful driver from

165. Symmetrical justification arguably rules out windfall benefits as well, but cases involving justification defenses rarely raise this issue.

166. See supra notes 76-84 and accompanying text (discussing the five types of condemnation, including the fourth type which condemns the defendant as one who violated a prohibitory norm as an accountable agent).

167. See supra notes $95-96$ and accompanying text (describing Jones). 
avoiding her. $\mathrm{X}$ causes bodily harm to the innocent child without fulfilling the culpability requirement for criminal assault or falling below the standard of reasonable care for tort liability. ${ }^{168}$

The law allows conduct that causes injury to innocent parties for several reasons. Proscribing conduct that might accidentally harm innocent people despite due care would require massive restrictions on individual liberty and economic activity such as driving and manufacturing. Laws prohibiting all intentional infliction of suffering on others would require severe sacrifice of other important values. Proscribing true harmful statements about others, for example, would entail a marked limitation of free expression. Finally, some circumstances simply do not provide an alternative course of action that does not injure some innocent party. The justification defense provided for defendants who choose the lesser evil explicitly addresses these cases.

In short, some justified violations of criminal offense definitions elicit ambivalent intuitive responses because the justification is asymmetrical, involving undeserved harm to some party, but many other legal acts elicit similar intuitive responses for the same reason. ${ }^{169}$ Justification defenses, like other legal provisions, sometimes fail to provide symmetrical justification for many reasons including those discussed. As exceptions to fully articulated prohibitory norms, justification defenses are unlikely to achieve complete symmetry unattained by the norms themselves. Conduct that fulfills a recognized justification defense, like conduct that violates no offense provision, fails to qualify for the fourth type of condemnation, even in circumstances in which it results in harm to an innocent party because it violates no fully articulated prohibitory norm.

168. MODEL PENAL CODE $\$ 211.1$ (Official Draft \& Revised Comments 1985) (assault); W. Page Keeton et al., PRosser aNd KeEton on tHE LAW OF TORTS $\$$ 29, 31 (5th ed. 1984) (regarding unavoidable accidents and due care).

169. Perhaps the most troubling cases are those, such as the flood case described previously, in which events create circumstances where some innocent parties must suffer and other innocent parties must decide how to direct that loss. See supra notes 163-165 and accompanying text (describing the flood case). 
Clearly, the conventional social morality represented by the revised social matrix demands much more fortitude of $\mathrm{C}$ in the original story than it demands of $\mathrm{D}$ in the revised version because $C$ must refrain from saving his own life, while $D$ must refrain from saving C's life. Should C and D both refrain from shooting, most observers would count $D$ as responsible but $C$ as heroic. Fortitude and heroism address character, praiseworthiness, and evaluation of actors, rather than external justification of acts. This case raises important issues that a fully satisfactory conventional social morality must address, but these are not issues of justification and exceptions to prohibitory norms. These issues involve evaluation of actors and the appropriate role of legal concepts such as excuse and mitigation in the social response to individuals who encounter extraordinarily demanding circumstances. Section III regarding duress returns to these issues.

Dressler's second case involves two parties competing for scarce and vital resources to which neither has a prior claim. $G$ and $\mathrm{H}$ survive a shipwreck and find themselves adrift at sea with no means to stay afloat except a single plank floating in the water. The plank is barely large enough to support one person. Each person can survive only by attaining sole possession of the plank, and neither has any prior claim to it nor any prior duty to the other. Either can release the plank, in which case the party who releases will die and the other will live. Alternately, both can hold on, leading to the death of both because the plank will not float with their combined weight. Finally, each can attempt to take the plank from the other. Arguably, either is equally justified in securing and defending the plank from the other, despite the fact that doing so assures the death of the other. This interpretation justifies both sides of the violent confrontation. ${ }^{170}$

This case raises a variety of technical issues. If either party takes the board from the other, the former will knowingly cause the death of the latter. If both hold onto the plank, however, both will

170. This case is an elaboration of the type of difficult case listed as 5.3 and introduced into the contemporary justification debate by Dressler, supra note 14 , at 88 . The author is putting aside the alternative of both letting go, and stipulating that no form of sharing will succeed. 
die. It seems, therefore, that each party causes both deaths merely by holding onto the board and can avoid committing homicide only by releasing the plank, sacrificing his own life. Yet, neither has any obvious obligation to sacrifice for the other. Perhaps fairness would suggest that both parties should hold onto the plank, understanding that it will not support both, because one person will probably become exhausted before the other and that person will drown, leaving the plank to the other, who can survive.

This story elicits conflicting intuitions, but it provides no reason to favor one party over the other. It seems, therefore, that either both parties are justified in holding onto the plank or in fighting for sole possession or neither party is so justified. If one thinks neither party is justified, this case raises no concern for the original or revised social matrices or for the incompatibility thesis. ${ }^{171}$ If one thinks both parties are justified, the justification arises from the desperate circumstances and the lack of preferable alternatives rather than from the unjustified conduct of the other because any circumstances justifying one must also justify the other as they encounter identical conditions. That is, if both parties are justified, then they do not justify otherwise illegal conduct by appeal to each other's justified behavior. Thus, this case remains consistent with the revised social matrix which precludes justification of otherwise illegal conduct by appeal to another party's justified conduct. ${ }^{172}$

If one thinks that both parties are justified, this case constitutes a counter-example to the original incompatibility thesis which denies that both parties in violent conflict can both be justified. Notice, however, that the term justification has wide and narrow senses in this area of discourse. In the narrow sense, a justified act is an otherwise illegal one which is rendered permissible by a justification defense. In the wide sense, a justified act is one which is permissible in light of all legally relevant considerations. Conduct justified in the wide sense includes but is not limited to conduct justified in the narrow sense. For example, certain acts are

171. See supra notes $35-37$ and accompanying text (describing the original matrix and incompatibility thesis).

172. See supra notes 161-162 and accompanying text (discussing the revised social matrix). 
justified in the wide sense, but not the narrow, because they are authorized by statute or simply because they are not forbidden by any offense definition. Officer Fife's intervention between Spike and Dudley is justified by statutory authorization. ${ }^{173}$ Jones's conduct in driving the Smith family laundry out of business is justified in the wide sense in that it does not violate any law. ${ }^{174}$ The parties who compete for the plank in this case are justified in the wide sense, if at all, in that they do not appeal to justification defenses to justify their conduct. Thus, their conduct is consistent with the revised social matrix.

The negative aspect of the original social matrix, which precludes interference in justified conduct, generates the incompatibility thesis as a corollary. ${ }^{175}$ The revised social matrix precludes justification in the narrow sense of otherwise illegal conduct by appeal to the behavior of other parties which is justified in the narrow sense. That is, one cannot establish a justification defense by finding justificatory significance in another's conduct when that behavior is justified by a justification defense. Selfdefense, for example, legitimizes the use of force only in response to unlawful aggression. ${ }^{176}$ The prison escape cases provide examples of potential conflict between the prisoner's conduct which is justified in the narrow sense, by appeal to the choice among evils, and the official's conduct which is justified in the wide sense, by the authorizing statute. ${ }^{177}$ Athletic contests such as boxing matches or football games exemplify conflicts among actors who are justified in the wide sense in that they engage in legally authorized athletic events. ${ }^{178}$ None of these cases violates the revised social matrix because they do not justify otherwise

173. See id. (describing Fife's intervention).

174. See supra note $95-96$ and accompanying text (describing the Jones laundry case).

175. See supra notes $35-37$ and accompanying text (discussing the original matrix and the incompatibility thesis).

176. MODEL. PENAL CODE § 3.04 (Official Draft \& Revised Comments 1985). The choice of evils defense appeals to the harmful effects avoided rather than to lawful or unlawful conduct. Id. $\S$ 3.02 .

177. See supra notes 151-155 and accompanying text (discussing this type of conflict).

178. The author has in mind here, for example, boxing matches conducted under the auspices of a state boxing commission. 
illegal conduct by appeal to another's behavior which is justified by a justification defense.

One can imagine bizarre circumstances which arguably exemplify violent conflicts between parties justified in the narrow sense. Suppose, for example, that $M$ and $N$ simultaneously pull knives and launch unprovoked and unlawful attacks at each other in an elevator. Both are victims of unlawful attacks they cannot avoid. Both can protect themselves only through defensive violence. Both were engaged in illegal conduct at the moment that the other attacked, but neither provoked the others attack through that illegal behavior. ${ }^{179}$ Both engaged in unlawful assaults at the moment they initiated their attacks, but these assaults immediately became mutually justified exercises of defensive force because each was the subject of the other's unprovioked assault. If this constitutes a case of mutually justified self-defense, it serves as a counterexample to the incompatibility thesis, but it remains consistent with the revised social matrix because both parties justify their conduct by appeal to the other's illegal assault. This case remains difficult to interpret because the aggressive acts constitute unprovoked assaults and externally justified self-defense simultaneously. Thus, the manner in which one interprets the case depends on the category one adopts as controlling. Plausible cases of violent conflict between parties justified in the narrow sense do not seem to arise. ${ }^{180}$

In short, the revised social matrix accommodates the troubling cases. One can identify certain conflicts in which both parties are justified in the wide sense, but it is difficult to find clear cases of mutually justified violence in the narrow sense, and it is this narrow sense which is directly relevant to the theory of justification defenses because only these cases involve the justificatory force of justification defenses and conduct that falls within their scope. It is not clear, however, that the incompatibility thesis fulfills an

179. Model Penal CODE \& 3.04(2)(b)(i) (Official Draft \& Revised Comments 1985) (discussing provocation in self-defense).

180. Although, having said this, the author is confident that at least one of his more perverse colleagues will concoct one. 
independent function in the theory of justification defenses. The original social matrix apparently generates the incompatibility thesis as a corollary and can address the relevant cases in terms of the duty not to resist justified conduct without appeal to the thesis. ${ }^{181}$ The revised social matrix accommodates the relatively clear cases, and the difficulty encountered with certain cases such as those involving $\mathrm{G}$ and $\mathrm{H}$ (contesting for the plank) or $\mathrm{M}$ and $\mathrm{N}$ (attacking in the elevator) reflects ambivalent intuitive judgments regarding justification. The revised social matrix addresses these cases without appeal to the incompatibility thesis.

The entire discussion of the technical grounds for liability and justification in the plank case seems to miss an important aspect of the dilemma faced by these parties. How can society demand of $G$ and $\mathrm{H}$ that they refrain from struggling for their lives in these circumstances? Can any social institution reasonably require that people sacrifice their lives or allow others to sacrifice them in order to save others? This case, like that of $\mathrm{C}$ in the flood case, raises questions regarding the reasonable limits on the demands any social institution can make on individuals. Section III advances a theory of justification defenses grounded in the nature of the moral condemnation inherent in criminal conviction and punishment. It accommodates many of the previously identified difficult cases in a conceptually coherent and morally defensible framework. Section IV proposes an interpretation of duress as an exculpatory claim of a type separate from justification or excuse, and it addresses the remaining difficult cases.

\section{DURESS}

\section{A. The Classification Problem}

The duress defense exculpates defendants for offenses they performed in response to an exercise of, or a threat of, coercive and unlawful force directed against the defendant by some other

181. See supra notes $137-138$ and accompanying text (discussing the incompatibility thesis as a corollary of the original matrix). 
party. ${ }^{182}$ These defendants commit crimes under circumstances that would lead many observers to the intuitive judgment that their offenses were not their fault because others made them behave that way.

Certain cases raised in the previous sections remain unresolved by the framework for justification defenses advanced in section $\Pi$. These cases share at least some properties with those that qualify for the duress defense. Although section II addresses the prison escape cases as candidates for justification, and as difficult cases raising the issue of mutually justified violent conflict, certain factors render them arguable candidates for excuse. ${ }^{183}$ Prisoners who face impending violence experience coercive threats which would elicit strong fear in most people. If they are unable to secure reliable official protection in the prison, then many observers might reasonably think that these defendants 'had no choice,' 'could not help it,' or 'could not control themselves.' These interpretations seem particularly apt when applied to individuals who run impulsively in panic rather than as part of a well-planned escape.

The analysis advanced in section $I I$ denies justification to the innocent $C$ for shooting the innocent $B$ when $C$ realizes that $B$ is about to redirect the flood waters, killing $C$ in order to save 1000 innocent townspeople. That discussion also recognizes that $\mathrm{C}$ would be heroic, however, if he should accept his fate in the face of such frightening prospects. ${ }^{184}$ The stranded sailors $G$ and $H$, who struggle for the only available plank, arguably engage in unjustified homicidal conduct toward each other. Many observers who would deny $\mathrm{G}$ and $\mathrm{H}$ a legal justification defense might question the decision to punish them because their circumstances left them no reasonable alternatives. ${ }^{185}$

182. MODEL PENAL CODE $\$ 2.09$ (Official Draft \& Revised Comments 1985); DEFENSES, supra note $3, \S 177$. In some jurisdictions the coercive force may be directed toward another party. See id. $\S 177(\mathrm{e})(4)$ (discussing the variations as to the identity of the parties). cases).

183. See supra notes 151-161 and accompanying text (discussing prison escape and related

184. See supra notes 163-170 and accompanying text.

185. See supra notes 170-172 and accompanying text. 
These three types of cases do not present the appropriate conditions for classic duress claims because the actors do not engage in their illegal conduct in response to orders from another party who exercises or threatens to exercise coercive force unless they comply. ${ }^{186}$ The actors in these three cases encounter circumstances similar to those encountered by defendants with standard duress claims, however, in that compliance with the law would result in severe and undeserved harm. Most people would probably experience extreme fear in these circumstances, and few people could confidently say that they would resist that fear in order to comply with the law.

\section{B. The Theoretical Interpretation}

Although duress is widely established as a criminal defense, the theoretical explication of the defense remains controversial. ${ }^{187}$ Certain aspects of the defense lend themselves to classification as a justification while other aspects seem more appropriate to an excuse. Some commentators have classified the defense as a justification, but most interpret it as an excuse. ${ }^{188}$

Those who classify duress as an excuse sometimes contend that this defense applies to defendants who are not culpable for their offenses because their conduct is not voluntary. Some commentators contend that those who are subject to severe coercive pressure to commit a crime have no real choice or are unable to control themselves; their wills are overborne by the force or threats of force. ${ }^{189}$ These claims remain extremely difficult to explicate. The conduct in question fulfills the voluntary act requirement, ${ }^{190}$ and the actors suffer no disorder such as paralysis or convulsion that severs the usual association between individual behavior and

186. DEFENSES, supra note $3, \S 177(\mathrm{e})(5)$.

187. Id. $\S 177$ (a) (documenting the wide-spread acceptance).

188. LAFAVE \& SCOTT, supra note $123, \S 5.3$ (duress as choice of evils justification); Dressler, supra note 47 , at $1349-67$ (reviewing the justification and excuse interpretations).

189. RETHINKING, supra note 3 , at 831; DEFENSES, supra note $3, \S 177$ (a).

190. MODEL PENAL CODE $\S 2.01$ (Official Draft \& Revised Comments 1985) (requiring a voluntary act in the technical sense of the term). 
psychological process such as deliberation and decision. Defendants raise the duress defense regarding conduct performed in an organized, goal directed, and often efficient manner. ${ }^{191}$

For this reason, Herbert Fingarette rejects the interpretation of duress as a claim of involuntariness, advancing an alternative interpretation of duress as a species of victimization. According to Fingarette, $X$ victimizes $Y$, giving rise to a duress defense for $Y$, when $X$ wrongfully intervenes in the situation in order to manipulate $\mathrm{Y}$ into performing the crime by making it appear to be the reasonable thing to do. $Y$ should be excused from the burden ordinarily associated with the crime because $Y$ is the victim who acts reasonably under the circumstances. ${ }^{192}$ Fingarette's account of duress as victimization provides an interesting analysis of the relationship between the defendant and the victimizer who exerts the coercive force. This relationship arguably lies at the center of the historical defense. In addition, it illuminates the relationship between duress and other variations of victimization which carry legal significance. ${ }^{193}$

Although victimization places duress in an interesting framework within which one can study its relationships to other legal issues, it does not provide an adequate formulation of duress as a criminal justification or excuse. Fingarette sometimes presents the victimized defendant as acting reasonably in the circumstances, but in other passages he describes the defendant as one who acts in a manner that appears reasonable to the defendant. ${ }^{194}$ This issue seems to parallel the distinction raised earlier in this paper between external and internal justification and, therefore, between justification and excuse. ${ }^{195}$ If the victimizer's intervention actually renders the defendant's conduct reasonable by systemic standards, why does duress excuse rather than justify the conduct

191. H. Fingarette, Victimization: A Legalist Analysis of Coercion, Deception, Undue Influence, and Excusable Prison Escape, 42 WASH. \& LEE L. REv. 65, 71-82 (1985).

192. Id. at $66,82-86,105-14$. This account would also apply to cases in which $\mathrm{X}$ tricks $\mathrm{Y}$ into committing a crime.

193. Id. at 86-104.

194. Compare id. at $66,86,104,108,117$ with id. at 105, 110-13.

195. See supra notes $119-128$ and accompanying text (discussing internal and external justification). 
as the lesser evil? Alternately, if it renders the conduct reasonable only in terms of the defendant's personal interests and standards, why would it have any affect on the status of the criminal conduct from the perspective of the criminal law? Finally, if the victimization only causes the offensive conduct to appear reasonable to the defendant, how does duress differ from the excuse provided for mistake regarding justification? ${ }^{196}$.

Perhaps most importantly, the victimization interpretation fails to accommodate an important subset of plausible duress cases in which the defendant realizes that the criminal conduct is not reasonable. Suppose K runs a day-care center where he takes care of several pre-school children, including his own. Mobsters enter the center, place a gun at the head of $K$ 's child and threaten to kill the child unless $\mathrm{K}$ identifies the children of a rival mobster on whom they intend to take revenge by killing his children. By identifying the mobster's two children, $\mathrm{K}$ trades two innocent lives for one. K's act would not satisfy the requirements of a lesser evils justification, but $\mathrm{K}$ would have a plausible argument for the duress defense. ${ }^{197}$ This argument would remain plausible, and perhaps even become more persuasive, however, if $\mathrm{K}$ admitted that he acted believing that his conduct was not reasonable, but "I was just too scared to say no." Perhaps the most intuitively credible duress defendants are those who suffer guilt and remorse for their action, admitting they knew they were doing wrong when they performed the criminal conduct but claiming they were so frightened that they did it anyway.

Dressler advances an interpretation of duress as an excuse that captures difficult duress cases such as K's and addresses the feature that cases 5.2, 5.3, and 5.4 have in common with duress. ${ }^{198}$ Dressler contends that duress is the excuse provided by the criminal justice system for those who commit crimes because they

196. DEFENSES, supra note $3, \S 184$ (a) (mistake regarding justification); see supra notes 129 136 and accompanying text (discussing putative justification).

197. Recall that neither the MPC nor Robinson adopt the homicide exception. See MoDer PENAL CODE $\$ 2.09$ (Official Draft \& Revised Comments 1985); DefENSEs, supra note 3, $177(\mathrm{~g})(1)$.

198. See supra § II summary case list (identifying cases $5.2,5.3,5.4$ ). 
encounter conditions demanding more courage than society can fairly demand of its citizens. In Dressler's view, defendants who raise the duress defense each claim "I am only human," and society exculpates them because they committed their crimes in response to threats that persons of "nonsaintly" moral strength cannot be expected to withstand. ${ }^{199}$ This formulation captures the plea advanced by $K$ regarding his identification of the mobster's children. 'I knew I should not give up two innocents to save one,' $\mathrm{K}$ explains, "but I am only human; I was too frightened of what would happen to my child if I refused them, as I knew I should.' Similarly the escaping prisoners in example 5.2, the innocent farmer $C$ in case 5.4, and the stranded sailors in example 5.3 all faced circumstances which arguably demanded more of them than a society can reasonably expect. ${ }^{200}$

Although Dressler's formulation of duress captures the intuitive significance of the circumstances that give rise to many claims of duress, it remains difficult to reconcile with an integrated system of excuses. Robinson contends that excuses conform to a basic structure consisting of a disability giving rise to an excusing condition. The disability is some abnormal condition of the individual which differentiates that person from the population in general and causes the excusing condition. The excusing condition, such as impairment in the actors' ability to voluntarily control their conduct or to understand the nature of their conduct, renders them not blameworthy for their illegal behavior. ${ }^{201}$

Defendants who qualify for excuses do not merit the fourth type of condemnation expressed by criminal punishment. ${ }^{202}$ Individuals who suffer disabilities such as severe psychopathology or mental subnormality, which give rise to excusing conditions,

199. Dressler, supra note 47 , at $1334,1363-67$.

200. Although Fletcher frames the excuse as one of involuntariness or overborne will, Dressler's interpretation is consistent with Fletcher's formulation of the issue as asking whether the defendant could "be fairly expected to resist." See RETHINKING, supra note 3, at 834-35 (discussing Fletcher's view).

201. DEFENSES, supra note $3,8 \S 25,161$.

202. See supra notes 76-84 and accompanying text (describing the five types of condemnation, including the fourth type condemning the defendant as one who violated a prohibitory norm as an accountable agent). 
lack the capacities of rational agency, at least regarding their conduct that violated the fully articulated prohibitory norm. ${ }^{203}$ Those who lack the capacities of rational agency do not violate the dictates of the criminal law as accountable agents, and hence the courts cannot appropriately subject them to the fourth type of condemnation which inheres in criminal punishment.

Certain excuses exculpate defendants who do not suffer disabilities giving rise to excusing conditions. Reasonable mistakes regarding justification, for example, exculpate those who act on those mistakes under the excuse discussed previously as putative justification. ${ }^{204}$ Although these defendants lack disabilities, situational factors render their mistakes reasonable and undermine attributions of culpability. These defendants possess the capacities of rational agency, but their illegal conduct is not appropriately attributed to them in their status as accountable agents because their nonculpable mistakes prevented them from bringing their capacities of accountable agency to bear on their decision to engage in that conduct. Their action-plans, which represent them as accountable agents, did not include the conduct which fulfills the objective offense elements. ${ }^{205}$ These defendants do not merit the fourth type of condemnation because they did not violate the criminal law in their status as accountable agents, although they generally possess the relevant capacities.

Duress defendants, in contrast to those who claim disability or mistake based excuses, possess the capacities of accountable agents and they have the knowledge which provides the opportunity to exercise those capacities. They act on action-plans which include the acts exemplifying the objective offense elements as intended components. Although excuses usually exculpate defendants who suffer some disability that differentiates them from most people, the "person of reasonable firmness" clause in the duress provision of the MPC appeals to the similarity between the defendant's

203. ScHopp, supra note $11, \S 6.5$ (discussing psychological disorder and the capacities of agency).

204. See supra notes 129-136 and accompanying text (regarding putative justification).

205. See supra notes 104-112 and accompanying text (discussing the nature and significance of action-plans). 
behavior and that which would have been expected from most reasonable people. ${ }^{206}$ This focus on situational factors and criteria generalizable across persons ordinarily applies more appropriately to justifications than to excuses. ${ }^{207}$

As usually formulated, duress apparently combines properties of justification and of excuse, yet it qualifies as neither. Many crimes committed under conditions that raise plausible duress claims do not qualify for justification because the defendants did not engage in conduct that society approves or encourages. ${ }^{208}$ The day-care operator $\mathrm{K}$ and the innocent farmer $\mathrm{C}$ (in case 5.4), for example, each promote the greater harm by sacrificing two or more innocent lives in order to save one. Yet neither suffers a disability or excusing condition that would ground an excuse other than duress.

Robinson identifies the state of coercion and the resultant inability to control behavior as the disability and excusing condition, respectively. ${ }^{209}$ As discussed previously, however, many duress defendants violate the law through organized, efficient, goal-directed conduct, demonstrating no indication of impaired ability to control their actions. ${ }^{210}$ Disabilities are abnormal conditions of actors, but a "state of coercion" does not constitute a condition of an individual. ${ }^{211}$ Coercion is "the application of force to control the action of a voluntary agent," and to coerce is "[t]o constrain or restrain (a voluntary or moral agent) by the application of superior force."212 Thus, a state of coercion is not a condition of an actor but rather a relationship between an actor and a source of power, usually another person or group. As

206. MODEL PENAL CODE $\S 2.09$ (Official Draft \& Revised Comments 1985) (addressing the person of reasonable firmness); DEFENSES, supra note $3, \S 177$ (a).

207. RETHINKING, supra note 3, at 761-62.

208. See supra notes 12-13 and accompanying text (discussing the distinction between justification and excuse).

209. DEFENSES, supra note $3, \S 177$ (c).

210. See supra note 191 and accompanying text. Robinson describes the excusing condition as comparable to the volitional component of some insanity standards. DEFENSES, supra note $3, \S$ 177(c); see SCHOPP, supra note 11, at 165-76 (analyzing these standards as vacuous).

211. DEFENSES, supra note $3, \S 25$ (b)(1) (regarding the disability).

212. II OXFORD ENGLISH DICTIONARY 457 (compact ed. 1977). 
such, it may carry exculpatory force, but it does not constitute a disability as Robinson defines it, nor is it a defective capacity similar to those that ground insanity or mental subnormality excuses.

These arguments do not deny the intuitive moral force of the coercive circumstances that raise strong claims of duress, but they raise serious question about the accuracy of classifying duress as an excuse as that category is usually understood. Defendants who raise this defense demonstrate neither standard excusing conditions nor disabilities that differentiate them from the general population. Duress does not undermine the fourth type of condemnation expressed by criminal punishment because these defendants possess the capacities of accountable agents, and they have the knowledge required to apply those capacities to the decision at hand. The "person of reasonable firmness" provision appeals to the similarity between these actors and most others rather than to any condition that differentiates them. ${ }^{213}$ The intuitive judgement that these people do not deserve punishment arises not from justification or excuse, but rather from the recognition that only saints or heros would have resisted the coercive circumstances they encountered. An adequate theory of duress should reflect the difference between this intuitive judgment and the corresponding intuitions underlying justification and excuse.

\section{Systemically Complete Mitigation}

The criminal law ordinarily addresses wrongful conduct committed by responsible agents under difficult circumstances through mitigation in sentencing. By mitigating the degree of punishment, the law recognizes the defendant as less blameworthy for any of several reasons including unusually difficult circumstances. ${ }^{214}$ If defendants raise the duress defense as a claim

213. MODEl Penal. CODE $\S 2.09$ (Official Draft \& Revised Comments 1985) (discussing duress).

214. Id. $\$ 7.01$ (2) (listing mitigating factors relevant to sentencing); H.L.A. HART, PUNISHMENT AND RESPONSIBILITY 14-16 (1968). 
of mitigation, rather than excuse, they contend that they deserve less punishment than most people who commit similar offenses because they are less blameworthy.

The criminal law constitutes a substantial component in the conventional morality adopted by a society as the framework required for cooperative social interaction. The role of mitigation in this framework differs significantly from that of excuse. Defendants who assert excuses contend that they did not act in the capacity of systemically accountable agents because they lacked either the capacities of rational agency or the knowledge required to apply those capacities to the behavior in question. ${ }^{215}$ Those who assert mitigating conditions, in contrast, acknowledge their standing as accountable agents but contend that certain recognized conditions render them less blameworthy than those who commit similar offenses under ordinary circumstances. When compliance with the law would require exceptional discipline or fortitude, they contend, then the blameworthiness and appropriate punishment of those who fail to comply decreases just as the praise deserved by those who comply increases. Mitigation ordinarily reduces the severity of punishment, however, rendering it apparently inadequate for $\mathrm{K}$ (the day-care operator), $\mathrm{C}$ (in the flood case), $\mathrm{G}$ and $\mathrm{H}$ (contesting the plank), and other defendants who act in circumstances that seem intuitively to render any punishment excessive.

If the criminal law represents the conventional social morality that we need for cooperative interaction, then one who is not blameworthy by the standards of the criminal law is not necessarily one who merits no blame at all by the most stringent moral standards, but rather one who displays the degree of moral discipline and fortitude that citizens must generally exercise in order to maintain the cooperative social process. Just as the criminal law does not forbid every type of wrongful conduct that critical morality would prohibit, it does not require the degree of moral discipline and fortitude that an ideal critical morality would

215. See supra notes 83,94 and accompanying text (discussing the fourth type of condemnation as applied to excuses). 
demand. Rather, the criminal law should proscribe those types of conduct which if generally engaged in would prevent effective social cooperation, and it should require the level of discipline and fortitude that citizens must generally exercise in order to maintain social cooperation.

Defendants who violate criminal proscriptions under extraordinarily coercive circumstances might commit unjustified and unexcused offenses despite exercising the degree of discipline and fortitude required by the conventional social morality. Recall $\mathrm{K}$, who identified the mobster's two children to protect his own child, and $\mathrm{C}$, who killed $\mathrm{B}$ in order to prevent $\mathrm{B}$ from redirecting the flood away from the town and toward $\mathrm{C}^{216}$ Neither $\mathrm{K}$ nor $\mathrm{C}$ qualifies for a justification defense because each sacrificed two or more lives in order to protect one. Neither suffered any disability or lack of information that would support an excuse. The degree of fortitude required for compliance with the law in circumstances such as those encountered by $\mathrm{K}$ and $\mathrm{C}$, however, may well exceed that which the criminal law generally requires in order to maintain cooperative interaction. Rarely must citizens sacrifice their own lives or those of loved ones in order to maintain a cooperative society.

On this view, the criminal law defines and enforces the degree of individual discipline and fortitude required to maintain cooperative social interaction by punishing those who fall below this level while committing unjustified and unexcused offenses. Offenders who fail to exercise the required discipline and fortitude are blameworthy by the standard of the conventional social morality and subject to punishment. Circumstances that demand unusual discipline and fortitude mitigate blameworthiness, reducing the appropriate punishment in criminal justice systems that punish in proportion to blameworthiness. Extraordinary circumstances may elevate the level of discipline and fortitude required for compliance beyond that which the conventional social morality demands for cooperative social interaction. People who confront such

216. See supra notes 196-197 and accompanying text (describing K); supra notes 163-165 and accompanying text (describing $C$ ). 
extraordinary circumstances might exercise more discipline and fortitude than a society can reasonably demand, yet fail to successfully resist the coercive pressure. $\mathrm{K}, \mathrm{C}, \mathrm{G}, \mathrm{H}$, and others who commit offenses in response to such extreme circumstances are not blameworthy by the standards of the conventional morality because they have not fallen below the level of discipline and fortitude required by those standards.

These offenders are neither justified nor excused, yet they are not appropriately subject to punishment in a system that punishes in proportion to blameworthiness because they are not blameworthy by systemic standards. As usually understood, legal punishment involves harsh treatment of an offender, for an offense, administered by an authority in such a manner as to express moral condemnation. ${ }^{217}$ The harsh treatment usually takes a form, such as incarceration, that expresses condemnation in that society, and the severity of the punishment is usually intended to reflect the degree of condemnation deserved by the offender. ${ }^{218}$ Individuals who commit offenses under extremely demanding circumstances merit conviction by the standards of the criminal justice system because they have fulfilled the offense elements without justification or excuse; however, they do not deserve punishment in a retributive system that punishes in proportion to blameworthiness because they are not blameworthy by the standards of the conventional social morality, which does not require heroic discipline and fortitude. ${ }^{219}$

217. HART, supra note 214, at 4-5; FEINBERG, supra note 78, at 95-118.

218. FEINBERG, supra note 78, at 98-101 (discussing the form of punishment as expressive).

219. I will not attempt to develop a complete theory of blameworthiness here. Some readers might contend, for example, that the degree of blameworthiness varies directly with the harmfulness of the offense committed and inversely with the severity of the coercive threats encountered. Others might argue that the severity of the coercive threat determines the degree of mitigation, while the harmfulness of the offense committed is relevant only to justification. One who endorses the former theory would contend that the blameworthiness of an actor such as $\mathrm{K}$ or $\mathrm{C}$ varies with the number of deaths they must cause, while an advocate of the latter theory would mitigate their blameworthiness in proportion to their threat, regardless of the number of deaths caused. On either theory, however, blameworthiness remains the central issue in mitigation, and sufficient external coercion can require such extraordinary discipline and fortitude as to render some offenders not blameworthy for some offenses by the standards of the conventional morality. For further discussion of blameworthiness and desert, see J. Feinberg, Justice and Personal Desert, in FEINBERG, supra note 78, at 55-94; GEORGE SHER, DESERT (1987). 
When extraordinary circumstances render the defendant inappropriate for blame by the standards of the system but do not provide any justification or excuse, then mitigation completely precludes the harsh treatment that expresses condemnation within the system, but it does not preclude conviction. Defendants who commit crimes under these conditions merit systemically complete mitigation leading to conviction without the harsh treatment that constitutes part of legal punishment. Conviction without harsh treatment would serve an important expressive purpose by vindicating the law that proscribes acts of these types, as defined at the level of generality available in the penal code, and by vindicating the standing of innocent victims by acknowledging that they were wronged. These purely vindicating convictions would also recognize, however, that the defendant acted under conditions such that they were not blameworthy by the standards of the conventional morality represented by the criminal law. ${ }^{220}$

Purely vindicating convictions differ significantly from suspended sentences. Courts sometimes sentence defendants to a conventional term of years but suspend that sentence pending successful completion of a period of probation. ${ }^{221}$ Courts ordinarily suspend a sentence in favor of probation for a variety of reasons including: The defendant is not considered dangerous; the defendant has a job and a family to support; the defendant is a promising candidate for rehabilitation; or the facilities for incarceration are overcrowded. ${ }^{222}$ In contrast to a purely vindicating conviction, a suspended sentence marks the defendant as blameworthy to the degree represented by the severity of that

220. Although this article specifically advocates the interpretation of duress as systemically complete mitigation leading to purely vindicating conviction, duress does not exhaust the appropriate scope of this approach. The innocent farmer $\mathrm{C}$ and the stranded sailors $\mathrm{G}$ and $\mathrm{H}$ do not qualify for duress as usually formulated, but they provide plausible candidates for systemically complete mitigation. Some codes, courts, and commentators categorize entrapment as a nonexculpatory policy defense, while others classify it as a form of excuse. If one understands entrapment as exculpatory, rather that as purely policy based, it may fit the pattern of mitigation better than that of excuse. I will not attempt an analysis of entrapment here. See DEFENSES, supra note 3, at § 209; LAFAVE \& SCOTT, supra note $123, \S 5.2$ (discussing entrapment).

221. MODEl PENAL CODE $\$ \$ 6.02,7.01$ (Official Draft \& Revised Comments 1985) (addressing the basis for suspended sentences and probation).

222. Id. \& 7.01(2). 
suspended sentence. Probation serves as a social instrument applied by the court for purposes of social policy and is revokable by the court upon violation of conditions precisely because the suspended sentence has been identified as the harsh treatment deserved by the blameworthy defendant. ${ }^{223}$ According to usual practice, courts apply probation and suspended sentences as a matter of mercy, efficiency, or social policy. ${ }^{224}$ In contrast, the purely vindicating convictions advocated here reflect considerations of justice grounded in blameworthiness and desert.

In some cases, courts may suspend sentences because they think that the defendant is not blameworthy and does not deserve harsh treatment for an offense committed in response to provocation or fear. One advantage of recognizing purely vindicating convictions as a separate type of verdict is that they would allow courts to treat these defendants differently than those who are blameworthy but receive suspended sentences for policy reasons. This alternative would enable the court to convict and release without suspended sentence, avoiding the inconsistency of setting a sentence that ostensibly measures blameworthiness and then releasing on suspended sentence because the defendant is not blameworthy.

\section{Two Potential Criticisms}

Potential critics might raise two objections to the proposed purely vindicating convictions. First, they might claim that this practice is inconsistent in that it implicitly asserts both that these defendants are appropriate subjects of condemnation and that they are not. Purely vindicating convictions vindicate just because they represent social condemnation of the defendant's conduct, they might contend, yet we withhold the harsh treatment on the premise that these defendants are not sufficiently blameworthy to merit the condemnation represented by punishment. Second, some critics might deny that exculpation under excuse differs from mitigation

223. ARTHUR W. CAMPBEL, THE LAW OF SENTENCING \$\$ 5.1, 5.3 (2d ed. 1991) (discussing social policies underlying probation and conditions of probation).

224. Id. $\$ 5.1$ (discussing social policies favoring probation). 
to purely vindicating conviction. In either case, the verdict rejects the claim that the act is justified but exempts the actor from punishment.

Neither of these two potential criticisms accurately applies to the proposed purely vindicating conviction. This proposal avoids contradiction because the apparent inconsistency actually reflects the complexity of the institution of punishment. Any particular case of legal punishment involves the application of a complex social institution of punishment to a particular person for a particular offense. ${ }^{225}$ In order to establish rules of relatively broad generality, the institution must define both offenses and conditions of culpability in terms of relatively broad properties that do not capture every morally significant factor.

Purely vindicating convictions reflect the separate functions of justification, excuse, and mitigation within the conventional morality represented by the criminal law, and they provide a legal devise through which officials can express the social judgement relevant to this conventional morality in a more precise manner. Vindicating convictions ratify the systemic prohibition of acts of the type performed by the defendants as defined at the level of generality available to the system, and they recognize these defendants as accountable agents who have committed offenses as defined by the code. ${ }^{226}$ These convictions also vindicate the standing of innocent victims by explicitly denouncing the criminal conduct. They withhold harsh treatment, however, in recognition of the specific factors that rendered conformity in these cases so difficult as to demand discipline and fortitude beyond that required by the conventional social morality. ${ }^{227}$

In short, purely vindicating convictions reaffirm systemic condemnation of acts of the type performed by the defendant but refrain from condemning this defendant as blameworthy for this

225. See supra notes 78-79 and accompanying text (discussing punishment at the levels of institution and application).

226. See supra notes $80-84$ and accompanying text (discussing the first and fourth types of condemnation as inherent in criminal punishment).

227. See supra notes $216-224$ and accompanying text (discussing duress as a defense addreasing cases requiring extraordinary discipline and fortitude). 


\section{3 / Justification Defenses And Just Convictions}

particular act due to the extremely demanding circumstances. As such, they provide a special legal devise for addressing defendants who commit offenses under conditions that warrant the first and fourth types of condemnation inherent in criminal punishment, but who do not merit the fifth type of condemnation as morally blameworthy by systemic standards. ${ }^{228}$ These convictions provide us with an official procedure for communicating to the defendant, you are a responsible person, and acts of the type you performed are prohibited, but we realize both that under those conditions we probably would have done the same thing and that cooperative social interaction does not require heroism.

Although purely vindicating conviction and excuse both exempt the actor from harsh treatment without approving of the act as permissible, they are not interchangeable. Excuses exempt defendants who manifest excusing conditions due to disabilities that undermine their status as accountable agents who are appropriately subject to punishment. ${ }^{229}$ In contrast, purely vindicating conviction provides a method for explicitly recognizing those situations in which responsible actors fail to conform to the law for reasons that neither justify their acts nor undermine their status as accountable agents, but which render punishment inappropriate in a system representing the conventional social morality required for cooperative social interaction. Categorizing these cases as excuses distorts them by directing attention away from the highly significant circumstances and toward nonexistent disabilities.

Some potential critics might argue that $\mathrm{K}$ (the day-care operator) and $C$ (the victim of the redirected flood) suffer disabilities in that they lack the capacities needed to conform in these circumstarices. This claim distorts the relevant notions of responsibility and disability. The disability that grounds an excuse must differentiate excusable defendants from the general population and give rise to an accepted excusing condition. ${ }^{230}$ Ordinarily, these disabilities deprive the offender of the capacities identified by

228. See supra notes 80-84 and accompanying text (discussing the five types of condemnation).

229. DEFENSES, supra note $3, \S 161$ (analyzing the structure of excuses).

230. Id. $\$ 161(\mathrm{a})$. 
Hart as capacity-responsibility. ${ }^{2 \dot{3} 1}$ On this understanding, "capacity-responsibility" refers to competence for a particular role; that is, the role of a citizen with the ability to participate as an accountable agent in the conventional social morality represented by the criminal law. ${ }^{232}$ Individuals posses the relevant capacities to greater or lesser degrees, and to say of persons that they are responsible in this sense is to say that they possess these capacities at least to the degree that we ordinarily require of persons before we hold them accountable under the law. Actors suffer disabilities relevant to these capacities when their level of ability falls below this norm defined by the minimally accountable citizen. Thus, the assertion that an actor who possesses the capacities of ordinary citizens suffers a disability because he fails to successfully conform in unusually difficult circumstances distorts this usual conception of capacity-responsibility by misrepresenting extraordinarily demanding circumstances as defective capacities.

In addition to distorting the relevant concepts, categorizing duress as an excuse distorts the expression of condemnation inherent in conviction and punishment, denigrating certain defendants and misleading concerned citizens. Justifications and excuses preclude conviction and punishment by rendering inappropriate the fourth type of condemnation ordinarily expressed by legal punishment. ${ }^{233}$ Justifications do so by creating exceptions to the prohibitory norms. Thus, actors who engage in justified violations of offense definitions do not violate fully articulated prohibitory norms. Excused actors violate such norms, but they do not do so in their capacity as accountable agents by systemic standards. Those who do not merit this fourth type of condemnation do not merit conviction and punishment which inherently expresses this type of condemnation.

231. See HART, supra note 214, at 227-30 (describing actors as responsible in this sense if they possess the capacities of understanding, reasoning, and control of their movement that enable most people to conform to the law).

232. Id. at 227-30 (recognizing capacity-responsibility as a necessary condition for moral liability and for criminal liability in most systems).

233. See supra notes 80-84 and accompanying text (discussing the five types of condemnation). 
Defendants who qualify only for duress, in contrast, violate fully articulated norms as accountable agents. ${ }^{234}$ Extraordinary circumstances undermine attribution of blameworthiness relevant to the fifth type of condemnation which is ordinarily expressed by punishment. These cases and systemically complete mitigation reveal the inadequacy of the previous explication of the condemnation inherent in punishment. ${ }^{235}$ According to that analysis, the only type of condemnation inherent in all institutions of punishment is the condemnation of act-types which occurs at the institutional level through the articulation of offense definitions. The fourth type of condemnation also inheres in conviction and punishment by any criminal justice system that is retributive in the minimal sense that it limits punishment to those who fulfill criteria of accountability. This analysis did not include the fifth type of condemnation among those inherent in punishment.

The formulation of duress as systemically complete mitigation suggests a more complete analysis of the fifth type of condemnation. Judges and jurors make determinations regarding both conviction and sentencing and they apply both personal and systemic criteria of blameworthiness. Conviction does not imply blameworthiness by either personal or systemic criteria. It does not imply that the defendant is blameworthy by the personal standards of the trier of fact because each trier's personal moral standards may differ from the legal criteria for the reasons discussed previously. ${ }^{236}$ Thus, triers of fact who make a serious effort to set aside their personal standards in favor of those contained in judicial instructions will sometimes bring verdicts that do not reflect their personal moral standards. It does not imply blameworthiness by systemic criteria because the criminal justice system addresses factors contributing to blameworthiness other than accountability

234. The word "only" in this sentence rules out cases in which the defendant also qualifies for excuse (e.g., subnormality) or justification (e.g., lesser evils).

235. See supra notes 80-84 and accompanying text (analyzing the types of condemnation inherent in punishment).

236. See supra notes $85-87$ and accompanying text (discussing the potential differences between legal standards and individual moral standards). 
through mitigating and aggravating considerations relevant to sentencing rather than through complete defenses. ${ }^{237}$

Punishment does not imply blameworthiness by personal standards for the same reasons that prevent conviction from doing so. ${ }^{238}$ Punishment implies blameworthiness by systemic standards, however, in retributive institutions that distribute punishment in proportion to blameworthiness because such a system cannot administer the harsh treatment that constitutes part of punishment to a defendant who is not blameworthy by systemic standards. That is, any punishment must imply blameworthiness by systemic standards in a retributive institution that punishes in proportion to blameworthiness. Thus, punishment by a criminal justice system which is retributive in this sense implies blameworthiness by the systemic criteria, but circumstances which demand discipline and fortitude beyond the level required by these criteria undermine the attribution of blameworthiness. Purely vindicating convictions provide courts in these retributive systems with a devise for addressing those cases in which the defendants violate fully articulated norms as accountable agents but do not merit condemnation as blameworthy by systemic criteria. In this manner, these convictions enable the court to articulate more precisely the judgment of the conventional social morality represented by the criminal justice system.

Some readers might accept the argument for systemically complete mitigation but contend that it should be categorized as a separate type of defense leading to acquittal rather than to purely vindicating convictions. Although such an interpretation would preserve the basic analysis of justification and duress advanced in this article, I prefer the fully vindicating conviction for the following reasons. As presently developed, our criminal justice system addresses circumstances that increase or decrease blameworthiness for a particular "crime through aggravation in

237. MOdel. PENAL CODE § 7.01(2) (Official Draft \& Revised Comments 1985) (listing - mitigating circumstances used in sentencing); CAMPBEL L, supra note 223, 84 (discussing aggravating and mitigating circumstances in sentencing).

238. See supra notes $85-87$ and accompanying text (discussing potential differences between legal and individual moral standards). 
sentencing. ${ }^{239}$ Current defenses which address defendant culpability, broadly construed, exculpate defendants either because they have not violated a fully articulated prohibitory norm by committing a legal offense, or because they have not done so as responsible agents. Failure-of-proof defenses address those who have not committed legal offenses. ${ }^{240}$ Justifications exculpate those who have not violated fully articulated prohibitory norms. ${ }^{241}$ Excuses exclude those who do not violate the norms as responsible agents. ${ }^{242}$ The approach advanced in section IV promotes conceptual consistency with this framework by classifying systemically complete mitigation as a sentencing issue rather than as a defense.

The purely vindicating conviction retains the explicit condemnation of this type of conduct at the systemic level, possibly enhancing the ability of many people, especially innocent victims, to accept the outcome. The vindicating conviction also affirms the broader structure by explicitly confirming the defendant's status as an accountable agent by systemic standards. Finally, the vindicating conviction recognizes the separate expressive functions of conviction and punishment in retributive institutions. That is, conviction condemns a particular type of conduct by an accountable agent, and punishment expresses the degree of blameworthiness attributable to that agent. Some might suggest, of course, that the entire current framework ought to be revised, but that issue extends well beyond the scope of this article. ${ }^{243}$

The classification of duress and similar cases within the broader framework of the criminal law carries significance beyond the

239. MODEL PENAL CODE § 7.01(2) (Official Draft \& Revised Comments 1985) (listing mitigating circumstances used in sentencing); CAMPBELL, supra note 223, $\$ 4$ (discussing aggravating and mitigating circumstances in sentencing).

240. See supra notes 113-127 and accompanying text (discussing failure-of-proof defenses).

241. See supra notes $92-94$ and accompanying text (discussing justifications as undermining the fourth type of condemnation).

242. See supra notes 83,94 and accompanying text (discussing excuses as undermining the fourth type of condemnation).

243. See, e.g., KARL MENNINGer, THE CRIME of PUNISHMENT (1968); Barbara WOOtTon, CRIME AND THE CRIMINAL LAW (1963) (both authors question the entire conceptual and normative structure of criminal responsibility as an institution of social regulation). 
quest for conceptual consistency. The currently dominant classification of duress as an excuse denigrates the identified defendants by misrepresenting them as lacking the capacities of accountable agents. Perhaps most importantly from the perspective of the expressive function of the criminal law, excusing these actors encourages the rest of us to mislead ourselves in a selfindulgent manner because it allows us to direct our attention toward the putative defects suffered by these particular individuals without confronting the uncomfortable likelihood that they acted as they did not because they differ from us but rather because they are very much like us. ${ }^{244}$

\section{CONCLUSION}

This Article advances a theoretical framework for the analysis of justification defenses as part of an integrated system of criminal law. The theory calls upon the condemnation inherent in conviction and punishment, the prospective and retrospective functions of justifications, and the distinction between internal and external justification as broad organizing principles for the analysis of these defenses. Courts rely on justification defenses retrospectively in order to identify conduct which is exempt from the conviction and punishment authorized by the general prohibitory norms as represented by the objective elements of offense definitions. Individuals rely on these defenses prospectively when they select action-plans in order to avoid those which include acts exemplifying fully articulated criminal proscriptions.

Those who act within the scope of justification defenses do not merit the condemnation inherent in criminal punishment. Legal conviction and punishment ordinarily expresses condemnation at five levels, but only the first type of condemnation, expressed at the institutional level by the proscription of certain act-types as criminal offenses, inheres in the institution of legal punishment. Specific applications of punishment in a retributive system also express condemnation of the actors who have violated fully

244. DEFENSES, supra note $3, \S 161$ (discussing excuses as based on disability). 
articulated prohibitory norms as accountable agents by systemic standards. Justification defenses exempt certain defendants who do not merit this type of condemnation because their actions do not violate a fully articulated norm.

Excuses, in contrast, exculpate those who violate such a norm but not in the capacity of accountable agents. Some excused defendants lack the capacities required to qualify them as accountable agents, while others lack the knowledge that would provide the opportunity to apply these capacities to the decision to perform the proscribed conduct. This latter group's action-plan selection is internally justified by the reasons they are aware of, although their conduct is not externally justified by all the relevant reasons that actually apply.

Justification defenses apply only to conduct which is externally justified and thus exempted from the fully articulated prohibitory norm. Justified behavior is permissible because it is not forbidden, although the actors who perform such conduct may be blameworthy if they are not internally justified. Putative justification excuses those actors who are internally justified in the selection of their action-plans which represent them as moral agents. Justifications create a matrix of social responsibility in that conduct justified by a justification defense neither grounds accomplice liability for those who assist through otherwise legal behavior, nor does it provide justification for those who resist or interfere through otherwise illegal conduct. This social matrix does not logically preclude the possibility of mutually justified violent conflict, although plausible cases of mutually justified violence are extremely difficult to devise.

Duress has traditionally been very difficult to classify as either a justification or an excuse, and so it should remain because it is neither. Duress represents part of a broader set of cases which should be subject to systemically complete mitigation resulting in purely vindicating convictions. In a retributive system that punishes in proportion to blameworthiness, this approach would accommodate defendants who do not merit blame by systemic standards and thus do not merit one type of condemnation inherent in punishment by these retributive systems. 
